\title{
Evolutionary analysis of Japan's nuclear wastewater discharge events considering the impact of participants' emotions
}

\section{Xu Xin}

School of Economics and Management, Tongji University https://orcid.org/0000-0002-0780-156X

Miaohui Liu ( $\square$ liumiaohui@tongji.edu.cn )

School of Economics and Management, Tongji University

Xiaoli Wang ( $\square$ xiaoli-wang@tongji.edu.cn )

School of Economics and Management, Tongji University

\section{Tao Zhang}

School of Economics and Management, Tongji University

Kang Chen ( $\nabla$ chenkang@dlmu.edu.cn )

School of Maritime Economics and Management, Dalian Maritime University

\section{Research Article}

Keywords: nuclear wastewater discharge, marine pollution protection, evolutionary game model, rankdependent expected utility, public emotion

Posted Date: March 25th, 2022

DOI: https://doi.org/10.21203/rs.3.rs-1339631/v3

License: (c) (i) This work is licensed under a Creative Commons Attribution 4.0 International License. Read Full License 


\section{Evolutionary analysis of Japan's nuclear wastewater discharge events considering the impact of participants' emotions}

Xu Xin ${ }^{\mathrm{a}}$, Miaohui Liu ${ }^{\mathrm{a}} *$, Xiaoli Wang ${ }^{\mathrm{a}, * *}$, Tao Zhang ${ }^{\mathrm{a}}$ and Kang Chen ${ }^{\mathrm{b}, * * *}$ ${ }^{a}$ School of Economics and Management, Tongji University, Shanghai, 200092, PR China; ${ }^{b}$ School of Maritime Economics and Management, Dalian Maritime University, Dalian, Liaoning, 116026, PR China

ORCID: 0000-0002-0780-156X (X. Xin); 0000-0003-1484-1209 (K. Chen).

E-mail: xinxu@tongji.edu.cn (X. Xin); liumiaohui @tongji.edu.cn (M. Liu); xiaoliwang @tongji.edu.cn (X. Wang); $1851046 @$ tongji.edu.cn (T. Zhang);

chenkang@dlmu.edu.cn (K. Chen).

* Corresponding author. E-mail: liumiaohui@ tongji.edu.cn

** Corresponding author. E-mail: xiaoli-wang@ @ongji.edu.cn

*** Corresponding author. E-mail: chenkang@dlmu.edu.cn

Mailing address for the * Corresponding author: Tongji Building A, Siping Road 1500, Yangpu District, Shanghai, 200092, PR China. 


\section{Evolutionary analysis of Japan's nuclear wastewater discharge events considering the impact of participants' emotions}

The Japanese government's decision to discharge nuclear wastewater from the Fukushima Daiichi Nuclear Power Plant into the sea on April 13, 2021 has aroused widespread concern around the world. The Japanese people, especially the fishermen, have expressed their long and strong dissatisfaction with this decision. Motivated by this background, this paper discusses an evolutionary game considering the impact of participants' emotions to explore the evolutionary stable strategies of both the Japanese government and Japanese fishermen. The results show that (i) The evolutionary stability strategies of the two sides of the game are different under different emotion combinations. Under the optimism of the fishermen, the fishermen's decision making is irrational, and the equilibrium strategy of the game between the two sides is not conducive to the fishermen. (ii) The emotions of the players will not only affect their own strategic choices but also affect the strategic choice intentions of other players. (iii) Reducing the cost of nuclear wastewater treatment is currently the most feasible way to reduce the probability of the Japanese government's discharge policy. Under the premise that the government chooses to discharge, no matter what the fishermen's emotions are, it is the fishermen's dominant strategy to strive for more subsidies for their own interests. The abovementioned findings can provide a decision-making reference for the Japanese government to formulate discharge strategies and for Japanese fishermen to protect their rights and interests.

Keywords: nuclear wastewater discharge; marine pollution protection; evolutionary game model; rank-dependent expected utility; public emotion

\section{Introduction}

On March 12, 2011, the Japanese government announced a leak of radioactive material from the Fukushima Daiichi Nuclear Power Plant (FDNPP) as a result of the earthquake (Amano, 2015). On April 11 of the same year, another 7.1 magnitude earthquake struck Fukushima, and Japan issued another tsunami warning and nuclear leak alert (Ethel et al., 2011). Due to 
the abovementioned successive earthquakes and tsunamis, the cores of FDNPP units 1 to 3 melted down. To cool the reactor cores, Tokyo Electric Power Company (TEPCO) continues to inject water into the containment of units 1 to 3. As of April 2021, 1.25 million tons of nuclear wastewater has been stored in the plant and is still increasing at a rate of 140 tons per day (Liu, Lyu, et al., 2021). TEPCO claimed that the wastewater storage tanks in the FDNPP will be fully filled in the fall of 2022 and that there is no more land available for the construction of large numbers of storage tanks. According to Buesseler (2014) and Steinhauser et al. (2014), this is the worst and most damaging nuclear accident worldwide since the Chernobyl nuclear disaster in 1986. Therefore, it is not surprising that how to deal with the huge amount of nuclear wastewater has always been the focus of governments and people around the world (Liu, Wang, et al., 2021; Yang et al., 2022).

Ten years after the earthquake, the Japanese government 'basically' decided to discharge nuclear wastewater from the FDNPP into the sea. On April 13, 2021, the Japanese government held a cabinet meeting and formally decided to discharge millions of tons of nuclear wastewater from the FDNPP into the sea after filtering and diluting it. The discharge activity is expected to begin in 2023. The Japanese government promises that the wastewater discharged will meet international standards and will not negatively affect human health or the marine ecosystem. However, there are still considerable studies in which the radionuclides contained in wastewater will spread to most of the Pacific Ocean within 57 days and to global waters with ocean currents within 10 years. In particular, radioisotopes with long half-lives in wastewater, such as ${ }^{3} \mathrm{H},{ }^{14} \mathrm{C},{ }^{106} \mathrm{Ru},{ }^{60} \mathrm{Co}$, and ${ }^{90} \mathrm{Sr}$, will continue to 
pose a potential threat to the environment and public health (Gallardo \& Marui, 2016; Iwasa et al., 2020; Okamura et al., 2016; Shozugawa et al., 2020).

When news broke that the Japanese government had decided to discharge nuclear wastewater, Fukushima fishermen, who had been plagued by the nuclear leak, were in an uproar. When fishing resumed in the limited area of Fukushima Prefecture in June 2012, some Fukushima fishermen set out to try to expand their fishing business. After ten years of efforts, the sales channels of Fukushima fisheries were restored to some extent, and the radiation test pass rate of the products was close to $100 \%$. However, once nuclear wastewater is discharged into the sea by the government, the fishermen's hard work will be wasted. Therefore, the Japanese people have launched several large protests. The public reaction to the proposed discharge of nuclear wastewater into the ocean was far from opposition but rather resembled a strong dissatisfaction. Although the Japanese government and TEPCO have provided explanations for the discharge of nuclear wastewater, they have never been accepted by the majority of the public at home and abroad (Butler et al., 2011; Fernandez et al., 2016; Zhang et al., 2022). It is foreseeable that the game between the government and fishermen will be a long and dynamic evolutionary process, and public emotion must be taken into account as an important factor.

Against this background, it is particularly important to explore the evolutionary stable strategies ( ESSs) between the Japanese government and fishermen considering emotional factors and to analyze the key factors affecting ESSs. This will help to provide the necessary reference for the Japanese government to make decisions on the discharge of nuclear wastewater, promote the improvement of the relationship between the government and the 
people, and advance the sustainable development of the ecological environment and human health. To this end, our paper aims to construct an evolutionary game model to answer the following two research questions:

(1) How can an evolutionary game model between the government and fishermen be developed considering public emotional factors?

(2) What kind of nuclear waste water disposal strategy should the Japanese government adopt considering its game with fishermen? How can Japanese fishermen defend their legitimate rights?

To answer the abovementioned research questions, we first construct the payoff matrix based on the actual situation of the Japanese government and Japanese fishermen. Then, we introduce emotional factors into the evolutionary game model to construct replicated dynamic equations of the stakeholders and discuss the ESSs under different emotions of the Japanese government and fishermen. Finally, by adjusting parameters in the game model, we explore the influence of each factor on the game to identify the key factors affecting the ESS. Overall, this paper makes the following two contributions.

First, we discuss the game relationship between the Japanese government and Japanese fishermen by capturing the research hotspots and applying evolutionary game theory. Currently, studies related to the wastewater treatment of the FDNPP mainly analyze the current situation of pollution and the ecological impact and less consider the pollution management strategy of the government. Some studies based on game theory mainly discuss the relationship between the Japanese government and neighboring countries and 
international organizations, and there is a lack of analysis of the relationship between various stakeholders within Japan. Thus, this paper fills the abovementioned research gaps by developing a game model considering the relationship between the Japanese government and fishermen.

Second, most studies use static game theory to discuss the game relationship between stakeholders, ignoring the long-term and dynamic nature of the nuclear wastewater discharge problem. We consider the actual relationship between the Japanese government and Japanese fishermen and extend the evolutionary game theory model by introducing the emotion factor. To the best of our knowledge, this is the first paper that considers evolutionary game relationships with emotional factors in the discussion of nuclear wastewater treatment decisions in Japan. By analyzing the ESSs between stakeholders under different emotion combinations, we provide effective theoretical guidance to advance the development of a scientifically sound nuclear wastewater treatment strategy in Japan.

The remainder of this paper is organized as follows. Section 2 reviews the literature related to this paper and identifies the research gap. Section 3 proposes the basic assumptions of the evolutionary game model and introduces rank-dependent expected utility (RDEU) theory. Meanwhile, stakeholders' ESSs under different emotion combinations are analyzed. In Section 4, numerical simulations are carried out, and the key elements affecting the game are discussed through sensitivity analysis. Finally, Section 5 concludes this paper and proposes several recommendations for the government and fishmen. 


\section{Literature review}

The research questions addressed in this paper are closely related to nuclear wastewater management and evolutionary game theory. Therefore, we use two subsections to develop an overview of each of these two topics.

\subsection{Potential impacts of nuclear wastewater discharge policy}

Numerous studies have confirmed that the radioactive substances contained in nuclear wastewater pose a great threat to the natural environment on which humans depend and to their own health (Clifford \& Zhang, 1994; Dufresne et al., 2018). Normile (2021) stated that unlike other radioisotopes with significant risks, such as ${ }^{131} \mathrm{I},{ }^{236} \mathrm{U},{ }^{240} \mathrm{P},{ }^{137} \mathrm{Cs}$ (Cléro et al., 2021; Tims et al., 2016; Tsabaris et al., 2021), the large amount of ${ }^{3} \mathrm{H}$ contained in nuclear wastewater from the FDNPP is more hazardous. Currently, approximately $1 \mathrm{PBq}^{3} \mathrm{H}$ is stored in storage tanks at FDNPP (de With et al., 2021). ${ }^{3} \mathrm{H}$ has a half-life of 12.43 years and is highly cyclic in the biosphere. Once ${ }^{3} \mathrm{H}$ enters the human body, it may cause radiation damage to humans, leading to cell death. ${ }^{3} \mathrm{H}$ may also be enriched in marine organisms, affecting species throughout the food chain (de With et al., 2021; Yankovich et al., 2011).

Through the Advanced Liquid Processing System (ALPS) developed in 2012, TEPCO claims to have filtered out radioisotopes other than ${ }^{3} \mathrm{H}$ after the treatment of nuclear wastewater. However, reports still indicate that $73 \%$ of nuclear wastewater treated with ALPS still exceeds Japan's discharge standards as of the end of 2019. According to Shozugawa et al. (2020) and Zhao et al. (2021), some other radioisotopes with longer halflives (e.g. ${ }^{60} \mathrm{Co},{ }^{90} \mathrm{Sr},{ }^{106} \mathrm{Ru}$ ) also frequently escape from ALPS. Among them, ${ }^{60} \mathrm{Co}$ can cause 
cell damage; ${ }^{90} \mathrm{Sr}$ greatly increases the risk of leukemia in humans; and ${ }^{106} \mathrm{Ru}$ has a long-term radiation risk to the environment (Khajeh et al., 2017; Khani et al., 2012). These substances can pose a potential threat to humans and the environment through complex pathways. In addition to the discussion of the impacts caused by discharges from life science and chemical perspectives, some scholars have recently assessed the negative impacts of Fukushima nuclear wastewater discharges from the perspectives of ecosystems (Tanaka et al., 2016), health literacy of Fukushima residents (Moriyama et al., 2020), and food safety perceptions of the Japanese population (Kuroda et al., 2021). The abovementioned literature shows that the Japanese public still has doubts about whether wastewater treated with ALPS can meet discharge standards and is pessimistic about the safety of Fukushima seafood.

\subsection{Evolutionary game theory}

Evolutionary game theory originated in the 1990s (Liu, Wang, et al., 2021). Unlike traditional static game theory, evolutionary games take inspiration from biological evolution theory and consider that the game equilibrium between players is formed through repeated participation in the game and trial and error (Weibull, 1997). Therefore, unlike traditional games that consider each player to be perfectly rational, evolutionary game theory considers each player to have limited rationality. Each player maximizes utility by repeatedly learning and adjusting its own strategy (Von Neumann \& Morgenstern, 2007). Therefore, the equilibrium state formed by evolutionary games is also called dynamic equilibrium (Gallardo \& Marui, 2016). In recent years, evolutionary games have played a pivotal role in disciplines such as economics, finance, and environmental science (Hanley \& Folmer, 1998) and are seen as an 
effective tool for exploring the interconnections between individuals in complex systems and the evolutionary trajectories of individual strategies (Coninx et al., 2018).

In recent years, evolutionary game theory has been widely used in the game analysis of stakeholders, especially in the research on the government's management of pollution activities of enterprises. For example, Xu et al. (2021) analyzed the game relationships among stakeholders related to inland waterway navigation pollution. A three-party evolutionary game model was constructed based on prospect theory, and numerical simulation experiments were carried out through system dynamics simulation methods. The simulation results show that to ensure that inland waterway shipping pollution is effectively managed, both upstream and downstream governments should actively implement supervision and ensure the use of clean energy by shipping companies through institutions and policies. For public-private partnership (PPP) projects in wastewater treatment, Estalaki et al. (2015) and Lv et al. (2021) constructed different evolutionary game models to analyze the dynamic game of stakeholders. Wang et al. (2021) discussed how energy investment companies promote the development of solar thermal power and nuclear power in the context of carbon neutrality. An evolutionary game model was constructed to analyze the cooperative game among energy investment companies, solar thermal power plants and nuclear power plants. The authors found that energy investment companies are the most willing to participate when all three stakeholders choose to cooperate. In the field of construction waste resource utilization, a multi-intelligent evolutionary game model was developed by $\mathrm{Su}$ (2020). The authors found that regulatory costs that were too high reduced the government's willingness to regulate, and penalties and subsidies that were too low were detrimental to the 
evolution of optimal strategies among stakeholders. Similar research has been expanded in research areas such as supply chain management (Sun et al., 2019), manufacturing (Chen \& Hu, 2018), marine environmental governance (Hujainah et al., 2018; Penz \& Polsa, 2018), marine environmental improvement across regions (Smith, 2018; Smythe \& McCann, 2018), and marine environmental legal systems (Cullen-Knox et al., 2017).

There are relatively few policy-oriented studies on the Japanese government's discharge of nuclear wastewater into the sea. Very recently, Liu, Lyu, et al. (2021) analyzed the wastewater discharge equilibrium strategies of discharging countries and other countries of interest using static games, RDEU games, and sequential games. In particular, the authors included emotional factors in the traditional game model framework. The results show that the most likely emotional state for countries of interest to prevent emitters from discharging nuclear wastewater is to remain pessimistic. Liu, Wang, et al. (2021) constructed a tripartite evolutionary game model to explore the ESSs of Japan, other countries, and international environmental protection organizations (IEPOs). It is shown that the cost of nuclear wastewater treatment, negative externalities of the marine environment, litigation compensation, international assistance from the IEPO, and the proximity coefficient between Japan and other countries are all the key factors affecting ESSs. Yang et al. (2022) proposed a gray and unknown preference framework of the graph model for conflict resolution. The proposed method can more comprehensively reflect the decision-making uncertainty caused by stakeholders' incomplete cognition of objective things. 


\subsection{Research gap}

Based on the review of the abovementioned literature, it can be found that the vast majority of studies have discussed the ecological risks involved in the discharge of nuclear wastewater in the context of governmental decision making in considering the discharge of nuclear wastewater. The few studies on Japan's policy of discharging nuclear wastewater also start from international relations and discuss the game relationship among countries or among countries and international organizations. Few studies have included public emotions in the modeling framework and discussed the relationship between the government and the public. However, the impact of emotions on the management of public emergencies has received widespread attention since the outbreak of COVID-19 (Liu, Lyu, et al., 2021). In recent years, some scholars have carried out game analysis considering public emotions around areas such as land acquisition (Hong et al., 2020), environmental pollution (Hao et al., 2019), and emergency management (Xiong \& Hou, 2012). To the best of our knowledge, only Liu, Lyu, et al. (2021) constructed an RDEU game model considering public emotions to analyze the impact of Japan's nuclear wastewater discharge policy on stakeholders. Unfortunately, the authors assumed that the stakeholders are perfectly rational and construct a static game model without considering the dynamics of the game process. However, the relationship between the government and fishermen is a domestic matter that should receive the same attention as international relations. In recent years, the government and fishermen have engaged in a long-term dialog, so the game strategy between the two should evolve dynamically, and static game theory does not apply here. Therefore, to fill the abovementioned research gap, we first make several assumptions and construct the payoff 
matrix. Then, RDEU theory is introduced into the evolutionary game, and replication dynamic equations considering the public emotion factor are constructed for different stakeholders. Next, we determine the key parameters that affect evolutionary equilibrium through numerical simulation. Finally, policy recommendations for the Japanese government and Japanese fishermen are provided to promote the change of the Japanese government's nuclear wastewater discharge policy and help Japanese fishermen insist on defending their interests to minimize their losses.

\section{Methodology}

\subsection{Basic assumptions}

To abstract the problem and construct the game model, we first introduce the following assumptions.

Assumption 1. The most immediate victims of Japan's nuclear waste discharges are Japanese fishermen. In the evolutionary game of Japanese nuclear wastewater discharge, the Japanese government and Japanese fishermen are involved. In the process of game playing, they constantly modify and improve their behaviors to pursue the maximization of their own utility; that is, they both satisfy the assumption of bounded rational stakeholders (Friedman, 1998).

Assumption 2. The Japanese government has two strategies: discharge or nondischarge. The probability that the Japanese government chooses the discharge strategy is $p(p \in[0,1])$, and the probability that the Japanese government chooses the nondischarge strategy is $1-p$. The probability that Japanese fishermen choose to accept the discharge 
strategy is $q(q \in[0,1])$, and the probability that they choose to oppose the discharge strategy is $1-q$.

Assumption 3. The cost of the discharge strategy chosen by the Japanese government is set as $C_{d}$, which is relatively small compared to the nuclear wastewater treatment costs $\left(C_{n}\right)$ (Liu, Wang, et al., 2021). Since the discharge of nuclear wastewater will produce negative externalities to the marine environment (e.g., the deterioration of the marine environment, the destruction of residents' living environment and the threat to people's lives and health), the negative externalities of the marine environment suffered by Japan are set as $N E$.

Assumption 4. When the Japanese government chooses the discharge strategy, Japanese fishermen accept the nuclear wastewater discharge policy. The fishermen themselves need to bear the negative impact $B$ of nuclear wastewater discharge on fisheries alone, including the damaged image of Japanese fisheries and the decline in demand, sales and price of seafood. As a result, the Japanese government's benefit is $-C_{d}-N E$, and the Japanese fishermen's benefit is $-B$. If the Japanese government chooses the discharge policy and the Japanese fishermen oppose the strategy, the Japanese government will have to bear the discharge cost $C_{d}$ and the negative externality loss $N E$ of the marine environment. Despite the opposition of the public, the Japanese government made a behavior contrary to public sentiment, resulting in damage to its reputation $R_{l}$. After nuclear wastewater is discharged into the ocean, it will have a series of negative effects on fishermen. To appease fishermen, the Japanese government needs to provide a subsidy $S$ for them. However, in real life, the subsidy $S$ is far less than the negative impact $B \quad(S<B)$. 
Therefore, the benefits for the Japanese government are $-C_{d}-N E-S-R_{l}$, while the opposition activities of fishermen, such as demonstrations and other protests, cost the fishermen $A$, so the benefit for the Japanese fishermen is $-B-A+S$.

Assumption 5. When the Japanese government chooses the nondischarge strategy, it will bear a huge cost of nuclear wastewater treatment $C_{n}\left(C_{n}>C_{d}\right)$. When the Japanese government chooses not to discharge nuclear wastewater and Japanese fishermen choose to accept its strategy, Japanese fishermen will have neither loss nor benefit, so the payoff is 0 , and the Japanese government gains $-C_{n}$. When the Japanese government chooses not to discharge nuclear wastewater and Japanese fishermen choose to oppose the strategy, the Japanese government and fishermen stand in the same position. At this time, the Japanese government's action is popular and gains reputation benefits $R_{e}$. Therefore, the payoffs for the Japanese government and fishermen are $-A$ and $-C_{n}+R_{e}$, respectively.

For convenience, the notations commonly used are summarized in Table 1.

Table 1 Model parameters and variable descriptions

\begin{tabular}{ll}
\hline Parameters & \\
\hline$C_{d}$ & The cost of nuclear waste water discharge \\
$C_{n}$ & Nuclear wastewater treatment costs \\
$N E$ & The negative externalities of marine environment faced by the \\
& Japanese government \\
$R_{l}$ & The Japanese government reputation losses \\
$R_{e}$ & Reputational gains for the Japanese government \\
$A$ & The cost of Japanese fishermen's protests \\
$B$ & The negative impact of nuclear wastewater discharges on the lives \\
$S$ & of Japanese fishermen \\
& The living allowance given by the Japanese government to \\
\hline Variables & Japanese fishermen \\
\hline$p$ & Probability of Japanese government choosing the discharge \\
$q$ & strategy
\end{tabular}




\subsection{The RDEU game model}

RDEU game theory was first proposed by Quiggin (1982) in 1982 and is a utility theory that considers the emotional factors of participants. It was later refined by Yaari (1987). RDEU models, like earlier models, are based on probability weight functions, but their weights are not applied to the probabilities of individual events but to cumulative probabilities. Here, we first present the basic definition of the RDEU model below.

Definition 1. If a random variable, say $X$, takes a value in set $\left\{x_{i}, i=1,2, \cdots, n\right\}, x_{i}$ satisfies the order $x_{1}>x_{2}>\cdots>x_{n}$, and $X$ obeys the probability distribution of $P_{r}\left\{X=x_{i}\right\}=p_{i}, \quad i=1,2, \cdots, n$, which satisfies $p_{i} \geq 0, p_{1}+p_{2}+\cdots+p_{n}=1$, then the rank of $x_{i}$ can be defined as Equation (1). The higher the rank of $x_{i}$ is, the higher the priority in decision-making.

$$
R P_{r}=P\left\{X \leq x_{i}\right\}=p_{i}+p_{i+1}+\cdots+p_{n} \quad i=1,2, \cdots, n
$$

Definition 2. The decision maker's preference can be represented by a real-valued function $V$, which can be defined by the utility function $u(\cdot)$ and the weight function $\pi(\bullet)$, i.e., $V=(X, u, \pi)=\sum_{i=1}^{n} u\left(x_{i}\right) \pi\left(x_{i}\right)$, where $\pi\left(x_{i}\right)$ represents the decision weight for $x_{i}$ and can be expressed by Equation (2).

$$
\pi\left(x_{i}\right)=W\left(p_{i}+1-R P_{i}\right)-W\left(1-R P_{i}\right) \quad i=1,2, \cdots, n
$$

The function $W(\bullet)$ represents the emotion function of the decision maker, and $W_{i}(x)=x^{r_{i}}, r_{i}>0, i=1,2$. Here, $r_{i}$ is called the emotion index of decision maker $i$, and the value of $r_{i}$ is arbitrary. If $r_{i}>1, W_{i}(x)$ is an optimism emotion function, the larger the emotion index $r_{i}$ is, the higher the degree of optimism of the decision maker. If $0<r_{i}<1$, 
$W_{i}(x)$ is a pessimism emotion function, the smaller the emotion index $r_{i}$ is, the higher degree of pessimism of the decision maker; if $r_{i}=1, W_{i}(x)$ is a no emotion function, and the decision maker is completely rational (Quiggin, 1990; Starmer, 2000).

\subsection{The RDEU evolutionary game model}

Suppose the mixed strategy of the Japanese government is $(p, 1-p)$, that is, the Japanese government chooses 'Discharge' with probability $p$ and 'Nondischarge' with probability $1-p$; the mixed strategy of Japanese fishermen is $(q, 1-q)$, i.e., the Japanese fishermen choose 'Accept discharge' with probability $q$ and choose 'Oppose discharge' with probability $1-q$. Since nuclear wastewater discharge is a public emergency, it is a more realistic consideration for us to introduce emotional factors into game analysis. Let the emotional function of the Japanese government be $w_{1}(p)=p^{r_{1}}$ and the emotional function of Japanese fishermen be $w_{2}(q)=q^{r_{2}}$, where $r_{1}$ and $r_{2}>0$ are the emotion indices of the Japanese government and Japanese fishermen, respectively. Based on the above discussion, the payoff matrix of the Japanese government and Japanese fishermen is shown in Table 2. The table shows that there are four strategy combinations (Discharge, Accept discharge), (Discharge, Oppose discharge), (Nondischarge, Accept discharge), (Nondischarge, Oppose discharge) in the game between the Japanese government and Japanese fishermen, and each player has four possible payoffs. The game process between the Japanese government and fishermen is illustrated in Fig. 1. 
Table 2 Payoff matrix of the Japanese government and Japanese fishermen

\begin{tabular}{ccc}
\hline Japanese Government & \multicolumn{2}{c}{ Japanese Fishermen $(F)$} \\
\cline { 2 - 3 }$(G)$ & Accept discharge $(q)$ & Oppose discharge $(1-q)$ \\
\hline Discharge $(p)$ & $-C_{d}-N E,-B$ & $-C_{d}-N E-S-R_{l},-B-A+S$ \\
Nondischarge $(1-p)$ & $-C_{n}, 0$ & $-C_{n}+R_{e},-A$ \\
\hline
\end{tabular}

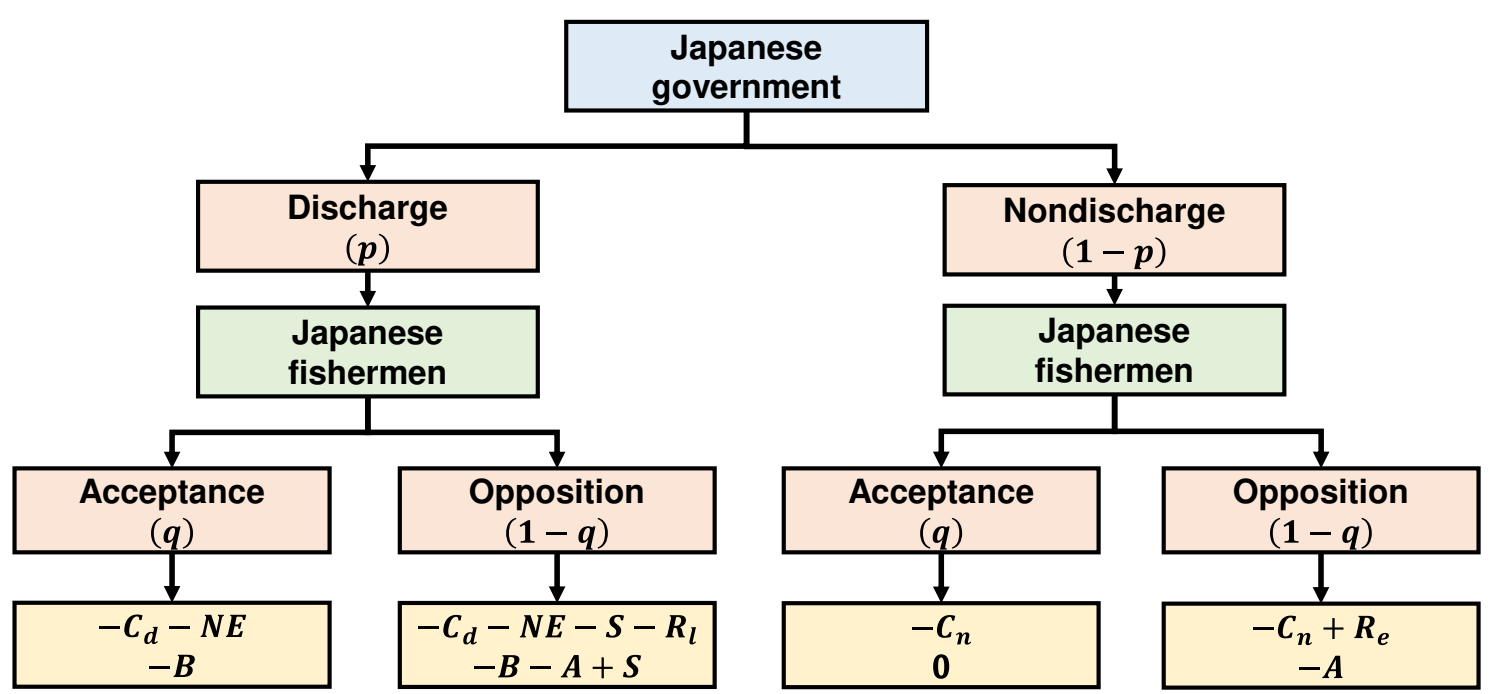

Fig. 1 A game model of nuclear wastewater discharge between the Japanese government and Japanese fishermen

According to the definition of rank and decision weight in RDEU theory, the probability distribution, rank and decision weight of the Japanese government $(G)$ and Japanese fishermen $(F)$, and the corresponding benefits can be obtained, as shown in Tables 3 and 4, respectively. According to the numerical values of nuclear wastewater treatment cost, nuclear wastewater discharge cost and the negative externalities of the marine environment that the Japanese government will face after nuclear wastewater discharge, the ranking of strategic benefits of the Japanese government is explained as follows:

After the Fukushima nuclear accident, the Japanese government proposed five kinds of nuclear wastewater treatment solutions, i.e., discharge nuclear wastewater into the sea, turn nuclear wastewater into water vapor and discharge it into the atmosphere, discharge nuclear 
wastewater into the depths of the ground along underground pipes, electrolytic treatment of nuclear wastewater, and solidification of nuclear wastewater into the ground. Among these options, the cost of discharging the treated water of nuclear wastewater into the sea is the lowest, while the treatment cost of other methods is dozens or even hundreds of times that of discharging it into the sea. From the perspective of cost and technical feasibility, the Japanese government has chosen to discharge nuclear wastewater into the sea among five options.

Therefore, the benefit of the Japanese government from not discharging nuclear wastewater should be much smaller than the benefit of discharging nuclear wastewater into the sea, so the order of benefits should be $-C_{d}-N E>-C_{d}-N E-S-R_{l}>-C_{n}+R_{e}>-C_{n}$.

Table 3 Probability distribution, rank, and decision weight corresponding to Japanese government benefit value

\begin{tabular}{cccc}
\hline $\begin{array}{c}\text { Japanese government } \\
\text { benefit value }\end{array}$ & Probability $p_{i}$ & $\begin{array}{c}\text { Rank Position } \\
R P_{1}\end{array}$ & $\begin{array}{c}\text { Decision Weight } \\
\pi\left(x_{1}\right)\end{array}$ \\
\hline$-C_{d}-N E$ & $p q$ & 1 & $W_{1}(p q)$ \\
$-C_{d}-N E-S-R_{l}$ & $p(1-q)$ & $1-p q$ & $W_{1}(p)-W_{1}(p q)$ \\
$-C_{n}+R_{e}$ & $(1-p)(1-q)$ & $1-p$ & $W_{1}(1-q+p q)-W_{1}(p)$ \\
$-C_{n}$ & $(1-p) q$ & $q-p q$ & $1-W_{1}(1-q+p q)$ \\
\hline
\end{tabular}

For Japanese fishermen, it is in their best interest that the government chooses not to discharge nuclear wastewater into the sea because any damage to the marine environment will have a negative impact on the living environment and livelihood of the fishermen. At the same time, any resistance requires a cost, so the order of the benefits of Japanese fishermen should be $0>-A>-B-A+S>-B$. 
Table 4 Probability distribution, rank, and decision weight corresponding to Japanese fishermen's benefit value

\begin{tabular}{cccc}
\hline $\begin{array}{c}\text { Japanese fishermen's } \\
\text { benefit value }\end{array}$ & Probability $p_{i}$ & $\begin{array}{c}\text { Rank Position } \\
R P_{2}\end{array}$ & Decision Weight $\pi\left(x_{2}\right)$ \\
\hline 0 & $(1-p) q$ & 1 & $W_{2}(q-p q)$ \\
$-A$ & $(1-p)(1-q)$ & $1-q+p q$ & $W_{2}(1-p)-W_{2}(q-p q)$ \\
$-B-A+S$ & $p(1-q)$ & $p$ & $W_{2}(1-p q)-W_{2}(1-p)$ \\
$-B$ & $p q$ & $p q$ & $1-W_{2}(1-p q)$ \\
\hline
\end{tabular}

According to the decision weights obtained in Tables 3 and 4, the RDEU expected utility function of the participants can be calculated, and the evolutionary game model with emotional parameters can be obtained. Let $U_{G D}$ represent the expected utility of the Japanese government adopting the strategy of discharging nuclear wastewater; $U_{G N}$ denotes the expected utility of the nondischarge strategy, and $U_{G}$ is the average expected utility. We can obtain the following relationships.

$$
\begin{gathered}
U_{G D}=\left(-C_{d}-N E\right) q^{r_{2}}+\left(-C_{d}-N E-S-R_{l}\right)\left(1-q^{r_{2}}\right) \\
U_{G N}=-C_{n} q^{r_{2}}+\left(-C_{n}+R_{e}\right)\left(1-q^{r_{2}}\right) \\
U_{G}=\left(-C_{n}+R_{e}\right)\left[W_{1}(1-q+p q)-W_{1}(p)\right]+\left(-C_{n}\right)\left[1-W_{1}(1-q+p q)\right] \\
+\left(-C_{d}-N E\right) W_{1}(p q)+\left(-C_{d}-N E-S-R_{l}\right)\left[W_{1}(p)-W_{1}(p q)\right]
\end{gathered}
$$

Moreover, we let $U_{F A}$ represent the expected utility of Japanese fishermen choosing to accept the discharge strategy; $U_{F O}$ denote the expected utility of the opposing discharge strategy; and $U_{F}$ is the average expected utility. The following equations can be obtained.

$$
\begin{gathered}
U_{F A}=-B p^{r_{1}} \\
U_{F O}=(S-B-A) p^{r_{1}}+(-A)\left(1-p^{r_{1}}\right)=(-B+S) p^{r_{1}}-A \\
U_{F}=0 W_{2}(q-p q)+(-A)\left[W_{2}(1-p)-W_{2}(q-p q)\right]+ \\
\left.(-B-A+S)\left[W_{2}(1-p q)-W_{2}(1-p)\right]+(-B)\right)\left[1-W_{2}(1-p q)\right]
\end{gathered}
$$


According to the basic method of the Nash equilibrium solution, when both sides of the game involved in the Japanese government's discharge of nuclear wastewater adopt mixed strategies, we take partial derivatives of $p$ and $q$ of the RDEU expected utility function Equations (4) and (5). Thus, the replicated dynamic equation can be written as follows.

$$
\begin{aligned}
G(p)=\frac{\mathrm{d} p}{\mathrm{~d} t} & =p^{r_{1}}\left(U_{G D}-U_{G}\right) \\
& =p^{r_{1}}\left[\begin{array}{l}
-C_{d}-N E-S-R_{l}+C_{n}+\left(S+R_{l}\right) q^{r_{2}}-R_{e}(1-q+p q)^{r_{1}} \\
+\left(-C_{n}+R_{e}+C_{d}+N E+S+R_{l}\right) p^{r_{1}}-\left(S+R_{l}\right)(p q)^{r_{1}}
\end{array}\right] \\
F(q)=\frac{\mathrm{d} q}{\mathrm{~d} t} & =q^{r_{2}}\left(U_{F A}-U_{F}\right) \\
& =q^{r_{2}}\left[-B p^{r_{1}}-A(q-p q)^{r_{2}}+(A-S)(1-p q)^{r_{2}}-(B-S)(1-p)^{r_{2}}+B\right]
\end{aligned}
$$

Let $G(p)=0, F(q)=0$; five system equilibrium points can be obtained, i.e., $(0,0),(0,1),(1,0),(1,1)$, and the mixed equilibrium point $\left(p^{*}, q^{*}\right)$. The stability of the equilibrium points can be analyzed using a standard Jacobian matrix ( $J$, see Equation (11) (Friedman, 1998). When the equilibrium point satisfies $\operatorname{tr}(J)<0$ and $\operatorname{det}(J)>0$, it is judged as the evolutionary stable strategy ( ESS ). In the Cartesian coordinate system, a point is the maximum value in one direction and the minimum value in the other direction; then, the point is a saddle point. When the determinant of the equilibrium point is negative, no matter whether the trace is positive or negative, the point is a saddle point (yielding a saddle) (Friedman, 1991).

The Japanese government and fishermen are both players in the game. However, unlike the rationality of the Japanese government in the decision-making process, fishermen are easily affected by subjective emotions during the game. Therefore, under the rational 
decision-making of the Japanese government, we consider the three emotions of Japanese fishermen: completely rational, emotionally pessimistic and emotionally optimistic. The following sections discuss the stability of the equilibrium point according to the different emotional states of the fishermen.

$$
\text { Jacobian Matrix }=\left[\begin{array}{ll}
\frac{\partial G(p)}{\partial p} & \frac{\partial G(p)}{\partial q} \\
\frac{\partial F(q)}{\partial p} & \frac{\partial F(q)}{\partial q}
\end{array}\right]
$$

\subsection{Evolutionary stability analysis}

When both sides of the game are rational, this situation means that their behavioral strategies are not affected by any personal emotions. At this time, we set the parameter of the emotion function to $r_{1}=r_{2}=1$. Bringing the emotion indices into each replicated dynamic equation, the stability of each equilibrium point is shown in Table 5.

Table 5 Stability analysis of the equilibrium point of the replicated dynamic system

\begin{tabular}{|c|c|c|c|c|c|c|c|c|c|}
\hline Model & \multicolumn{3}{|c|}{ Fishermen rational } & \multicolumn{3}{|c|}{ Fishermen pessimistic } & \multicolumn{3}{|c|}{ Fishermen optimistic } \\
\hline Emotion & \multicolumn{3}{|c|}{$r_{1}=1$} & \multicolumn{3}{|c|}{$r_{1}=1$} & \multicolumn{3}{|c|}{$r_{1}=1$} \\
\hline indices & \multicolumn{3}{|c|}{$r_{2}=1$} & \multicolumn{3}{|c|}{$r_{2}=1 / 3$} & \multicolumn{3}{|c|}{$r_{2}=2$} \\
\hline $\begin{array}{c}\text { Equilibrium } \\
\text { points }\end{array}$ & $\operatorname{tr}(J)$ & $\operatorname{det}(J)$ & State & $\operatorname{tr}(J)$ & $\operatorname{det}(J)$ & State & $\operatorname{tr}(J)$ & $\operatorname{det}(J)$ & State \\
\hline$(0,0)$ & + & + & $\begin{array}{c}\text { Instability } \\
\text { point }\end{array}$ & + & + & $\begin{array}{l}\text { Instability } \\
\text { point }\end{array}$ & + & 0 & $\begin{array}{c}\text { Instability } \\
\text { point }\end{array}$ \\
\hline$(0,1)$ & + & - & $\begin{array}{c}\text { Saddle } \\
\text { point }\end{array}$ & + & - & $\begin{array}{l}\text { Saddle } \\
\text { point }\end{array}$ & - & - & $\begin{array}{c}\text { Saddle } \\
\text { point }\end{array}$ \\
\hline$(1,0)$ & - & + & ESS & - & + & ESS &,-+ & 0 & $\begin{array}{l}\text { Instability } \\
\text { point }\end{array}$ \\
\hline$(1,1)$ & - & - & $\begin{array}{l}\text { Saddle } \\
\text { point }\end{array}$ & + & - & $\begin{array}{l}\text { Saddle } \\
\text { point }\end{array}$ & - & + & ESS \\
\hline$\left(p^{*}, q^{*}\right)$ & & & No stabl & olutio & depend & ig on specif & situat & & \\
\hline
\end{tabular}

It can be seen from Table 5 that when both sides of the game are rational, the equilibrium point $(0,0)$ is an instability point. The points $(0,1)$ and $(1,1)$ are saddle 
points. $\left(p^{*}, q^{*}\right)$ exists only under certain conditions, and $(1,0)$ is the evolutionarily stable point. These results show that when there is no emotional intervention between the Japanese government and Japanese fishermen, the Japanese government will definitely choose the discharge strategy, while Japanese fishermen will choose to oppose the discharge of nuclear wastewater, (Discharge, Oppose discharge) is the ESS .

Considering the degree of Japanese people's opposition to the government's decision to discharge nuclear wastewater into the sea in reality, we do not think Japanese fishermen will be as optimistic about the policy as they are pessimistic. Therefore, it is assumed that the emotion indices of Japanese fishermen under pessimism and optimism are $r_{2}=\frac{1}{3}$ and $r_{2}=2$, respectively. For instance, the latest questionnaire results of Japan's 'Asahi Shimbun' show that among the 42 mayors surveyed in Japan's Fukushima, Miyagi and Iwate prefectures, approximately $60 \%$ oppose the discharge of nuclear wastewater from the Fukushima Daiichi nuclear power plant of Tokyo Electric Power Company into the sea. At the same time, the government's decision was opposed by approximately $70 \%$ of Fukushima people (Liu, Lyu, et al., 2021; Liu, Wang, et al., 2021).

When the Japanese government is a rational participant in the game process, Japanese fishermen are pessimistic about the nuclear wastewater discharge incident. Bringing the emotion indices $r_{1}=1$ and $r_{2}=\frac{1}{3}$ into each replicated dynamic equation, the stability of each equilibrium point can be obtained in Table 5. One can see that $(0,0)$ is an instability point, $(0,1)$ and $(1,1)$ are saddle points, $(1,0)$ is an evolutionarily stable point, and $\left(p^{*}, q^{*}\right)$ only exists in certain circumstances in a stable solution. This shows that when the 
Japanese government is rational and the fishermen are pessimistic, the fishermen will inevitably choose to rise up and defend their interests, while the Japanese government will still choose to discharge nuclear wastewater into the sea. (Discharge, Oppose discharge) is the ESS.

When the situation is that the Japanese government is rational, Japanese fishermen are optimistic in the evolutionary game. It can be seen from Table 5 that different from the results of the above two scenarios, the evolutionary equilibrium strategy has changed. Bringing the emotion indices $r_{1}=1$ and $r_{2}=2$ into replication dynamic equations, the obtained points $(0,0)$ and $(1,0)$ are instability points, $(0,1)$ is a saddle point, $(1,1)$ is

the evolutionarily stable point, and $\left(p^{*}, q^{*}\right)$ can only be obtained under certain circumstances. The abovementioned results show that when the Japanese government is rational and the fishermen are optimistic, although the Japanese government chooses the discharge policy, the optimistic Japanese fishermen choose to accept the government's move. Even if this policy greatly harms their interests, strategy (Discharge, Accept discharge) is the ESS

\section{Numerical simulation}

With the continuous fermentation of Japan's nuclear wastewater discharge event, the conflict of interest between the Japanese government and Japanese fishermen is becoming increasingly tense. Based on the RDEU evolutionary game model between the Japanese government and Japanese fishermen, this section analyzes the corresponding path evolution and the influence of parameters considering the different emotions of fishermen. In addition 
to simulating the evolution results of two players in different emotion combinations, we will discuss the effect of different parameters on the evolutionary equilibrium, e.g., nuclear wastewater discharge costs, nuclear wastewater treatment costs, reputation losses, reputational gains, the negative externalities of the marine environment, Japanese fishermen's protest costs, the negative impact on the lives of Japanese fishermen, and subsidies.

\subsection{Evolution trajectories and numerical value simulation in three scenarios}

Based on the RDEU replicated dynamic equation and stability conditions, the ESSs under each scenario in Section 3.3 are simulated through MATLAB R2019b. According to the constraints of the model parameters and Liu, Wang, et al. (2021), the parameters are set as

follows: $C_{d}=3, N E=12, C_{n}=25, R_{e}=2, R_{l}=4, S=2.5, A=1$, and $B=5$.

\subsubsection{Evolution trajectories in three scenarios}

The probability $p$ that the Japanese government chooses to discharge nuclear wastewater and the probability $q$ that Japanese fishermen choose to accept the strategy are both constantly changing in $(0,1)$. According to the replicated dynamic equation, the evolutionary trajectories in three different combinations of emotions are depicted in Fig. 2. Considering that most fishermen would not support the discharge policy at this time, $q$ is set as 0.2 to indicate the pessimistic initial intention of Japanese fishermen. 


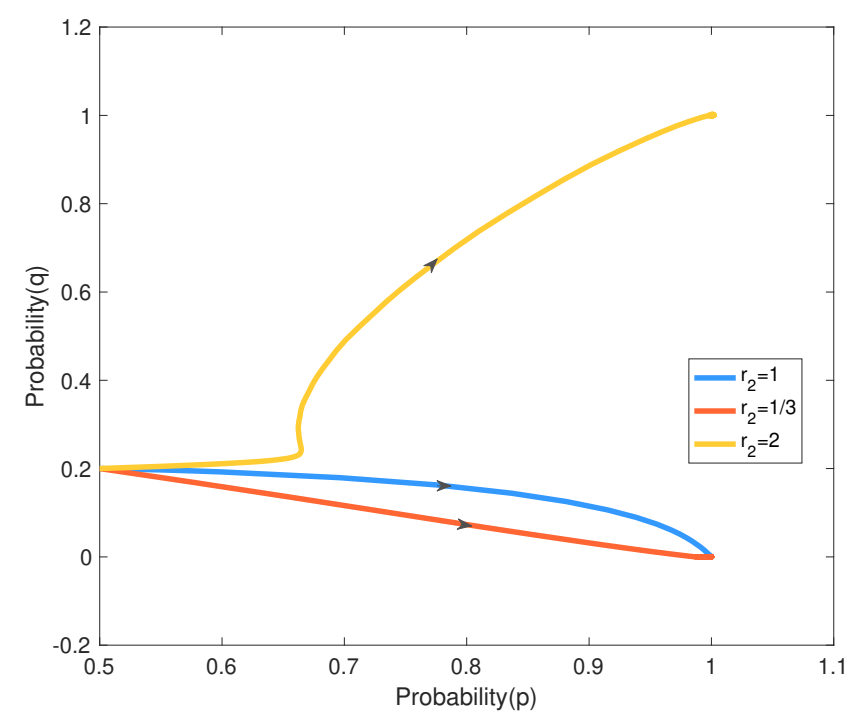

Fig. 2 Evolutionary trajectories in three different combinations of emotions

When both parties are rational game subjects, according to the replicated dynamic equation, the evolutionary trajectory of the Japanese government and Japanese fishermen can be obtained, and $(1,0)$ is the stable equilibrium point. Taking the initial willingness $p=0.5, q=0.2$, when $r_{1}=r_{2}=1$, the evolutionary trajectory of $(1,0)$ is shown by the blue line. The Japanese government, as a powerful political party, has absolute control and initiative in the process of nuclear wastewater discharge. After learning that fishermen are opposed to nuclear wastewater discharge, the Japanese government quickly adjusted its strategy to make the nuclear wastewater discharge strategy more effective. The probability that the Japanese government chooses the discharging strategy gradually approaches 1 . To defend their own rights and interests, the probability of rational fishermen choosing to accept the nuclear wastewater discharge policy gradually approaches 0 , and they all choose to oppose the policy through protests and other forms; then, the probability of opposing the discharge strategy approaches 1 . The final result of the evolutionary game is stable at $(1,0)$. 
When the Japanese government is rational and Japanese fishermen are pessimistic, taking the initial willingness $p=0.5, q=0.2$ and emotion indices $r_{1}=1, r_{2}=\frac{1}{3}$ into the replicated dynamic equations, we can obtain $(1,0)$ as the stable equilibrium point. The evolutionary trajectory of $(1,0)$ is shown in Fig. 2 by the orange line. When Japanese fishermen are pessimistic, although Japanese fishermen oppose the discharge of nuclear wastewater into the sea, the Japanese government still ignores the livelihood and safety of Japanese fishermen and chooses to discharge nuclear wastewater into the sea. Compared with the decision in which both parties are rational, when the fishermen are pessimistic, they do not think that the government will take their interests into account, and they will immediately choose the opposition strategy to defend their own interests. The probability of choosing the opposition strategy rapidly evolves from 0.8 to 1 to defend their own rights and interests. However, the firm opposition of the fishermen only accelerated the Japanese government's discharge policy, which is manifested in the acceleration of the probability of discharge from 0.5 to 0.95 , and then the probability that the Japanese government discharges nuclear wastewater into the sea gradually evolves to 1 .

It can be seen from Fig. 2 that when the Japanese government is rational and Japanese fishermen are optimistic, the evolutionary equilibrium strategies of the Japanese government and fishermen are different from the previous two scenarios. Introducing the initial willingness $p=0.5, q=0.2$ and emotion indices $r_{1}=1, r_{2}=2$ into the replicated dynamic equations, $(1,1)$ becomes the stable equilibrium point. This means that the Japanese government finally chooses the discharge strategy, while fishermen accept the government's discharge policy. The evolutionary trajectory of $(1,1)$ is shown by the yellow 
line. With the increasing probability that fishermen choose to accept the nuclear wastewater discharge policy, the probability that the Japanese government chooses to discharge nuclear wastewater into the sea increases sharply from 0.5 to 0.67 at first. After gaining the belief that weak fishermen choose to accept the discharge policy, the government quickly adjusts its own strategy and makes the probability of the nuclear wastewater discharge strategy close to 1. By comparing the evolutionary equilibrium strategies of the two parties under the first two emotion combinations, when fishermen are optimistic, their strategic choices will make their situation worse than in the first two cases.

In addition, when the Japanese government and Japanese fishermen are rational players, the process of the whole evolutionary game will be relatively calm and slow. However, when the game participants are emotional, the evolution trajectory shows that the process of the evolution of both sides will be relatively intense and rapid.

\subsubsection{Numerical value simulation in three scenarios}

When the Japanese government and Japanese fishermen are rational game subjects, according to the dynamic differential equation, the numerical change diagram of the dynamic evolution of both parties can be obtained, as shown in Figs. 3(a)-3(b), respectively.

Bringing each parameter value into the replica dynamic equation of the Japanese government, the dynamic differential equation of the Japanese government can be obtained: $G(p, q)=1.1 p+8.5 p q-8.5 p^{2} q-1.1 p^{2}$. It can be seen from Fig. 3(a) that this function is convex, i.e., the second derivative value is negative, indicating that $p=1$ is the stable strategy. Thus, the Japanese government will choose the discharge strategy. In the same way, 
we can obtain the dynamic differential equation of the fishermen as $F(p, q)=1.1 p+8.5 p q-8.5 p^{2} q-1.1 p^{2}$. From Fig. $3(b)$, we can see that $p=0.4$ is the critical point; when $p \in(0,0.4)$, this part is a convex function, i.e., the second derivative is negative, indicating that $q=1$ is the stable strategy; when $p \in(0.4,1)$, this part is a concave function and $q=0$ is the stable strategy. Obviously, when both sides are rational, the Japanese government will only choose to discharge nuclear wastewater into the sea for its own benefit. Since the probability of the Japanese government choosing the discharge strategy is 1 , which is greater than the critical value of 0.4 , Japanese fishermen will choose to oppose the discharge of nuclear wastewater.

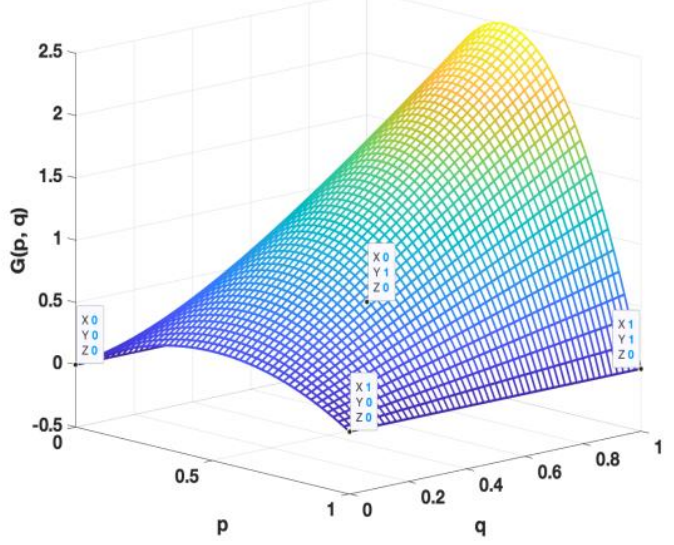

(a)

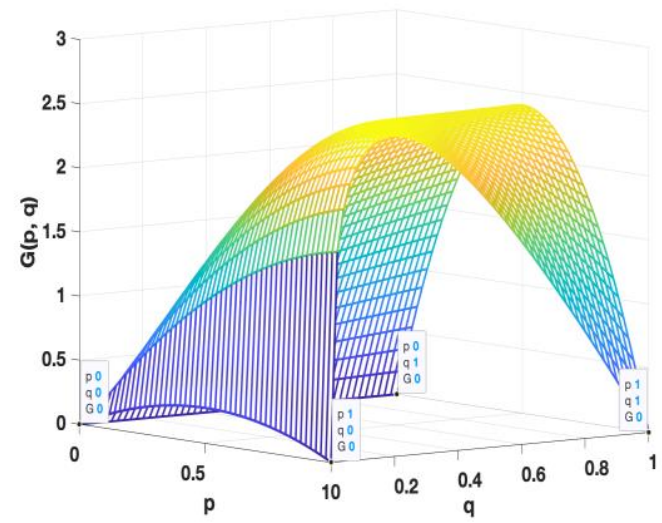

(c)

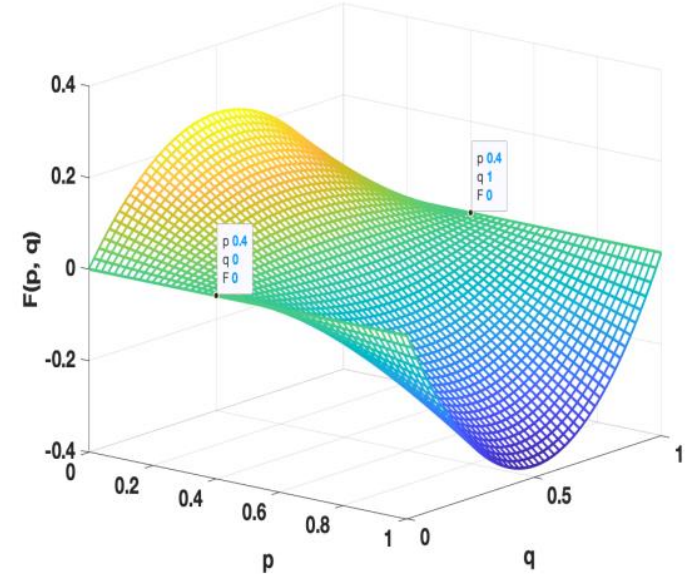

(b)

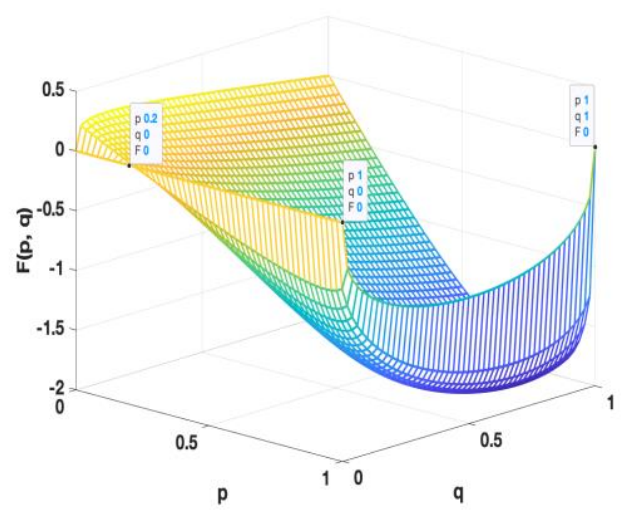

(d) 


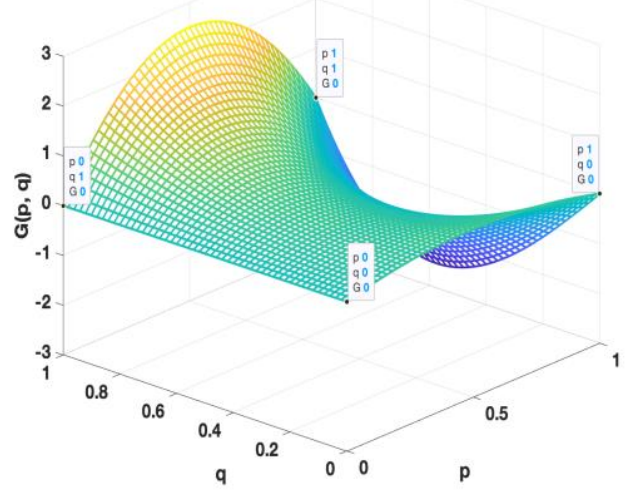

(e)

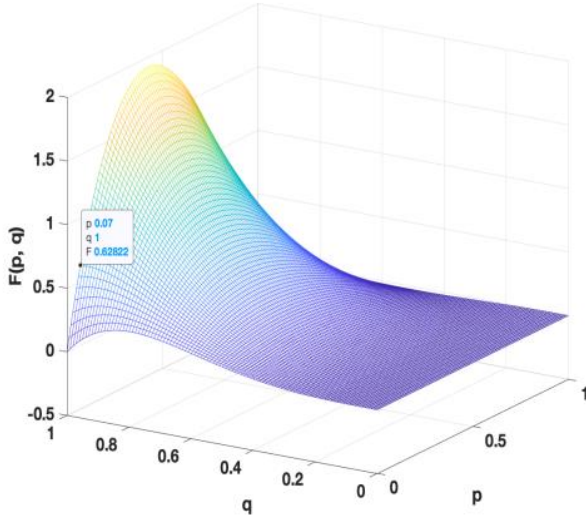

$(f)$

Fig. 3 Numerical variation diagram of dynamic evolution in three scenarios

Under the situation that the Japanese government is rational and Japanese fishermen are pessimistic, the numerical variation depicted by differential equations is shown in Figs. 3(c)- 3(d), respectively.

Introducing the parameter values into the replica dynamic equations, we can obtain the dynamic differential equation of both sides. The dynamic differential equation of Japanese fishermen is $G(p, q)=1.1 p+6.5 p q^{\frac{1}{3}}-8.5 p^{2} q+2 p q-1.1 p^{2}$. It can be seen from Fig. 3(c) that this function is convex, that is, the second derivative value is negative, indicating that $p=1$ is the stable strategy, and the Japanese government will definitely choose the discharge strategy. The dynamic differential equation of the Japanese fishermen is $F(p, q)=q^{\frac{1}{3}}\left[-5 p-(q-p q)^{\frac{1}{3}}-1.5(1-p q)^{\frac{1}{3}}-2.5(1-p)^{\frac{1}{3}}+5\right]$. Figure $3(d)$ shows that $p=0.20$ is the critical point. When $p \in(0,0.2)$, this part is a convex function, indicating that $q=1$ is the stable strategy. However, when $p \in(0.2,1)$, this part is a concave function, and $q=0$ is the stable strategy. Fishermen under pessimism tend to choose confrontational 
strategies of struggle, so when the rational Japanese government chooses the discharge strategy, the fishermen will choose the opposition strategy.

Next, we discuss the scenario in which the Japanese government is rational and Japanese fishermen are optimistic, which has different evolutionary results from the above two emotion combinations. According to the dynamic differential equation, the numerical change diagram of the dynamic evolution of the Japanese government and Japanese fishermen can be obtained, as shown in Fig. 3(e) -3(f), respectively. The dynamic differential equation of the Japanese government is $G(p, q)=1.1 p+2 p q+6.5 p q^{2}-8.5 p^{2} q-1.1 p^{2}$. It can be seen from Fig. 3(e) that this function is convex, that is, the second derivative value is negative, indicating that $p=1$ is the stable strategy, and the Japanese government will choose the discharge strategy. The dynamic differential equation of the Japanese fishermen is $F(p, q)=q^{2}\left[-5 p-(q-p q)^{2}-1.5(1-p q)^{2}-2.5(1-p)^{2}+5\right]$. Figure $3(f)$ shows that $p=0.07$ is the critical point. When $p \in(0,0.07)$, this part is a convex function, indicating that $q=1$ is the stable strategy, and when $p \in(0.07,1)$, this part is a concave function and $q=0$ is the stable strategy. It can be seen from the above analysis that under rational conditions, when the government chooses to discharge, choosing to resist should be the optimal strategy for the fishermen. However, the results of the evolutionary game show that when fishermen are optimistic, accepting the discharge policy is their equilibrium strategy. This means that when fishermen are optimistic, their decisions are irrational.

\subsection{Impacts of parameters on evolutionary trajectories and result}

Considering that each parameter will also have an impact on the decisions of the Japanese 
government and fishermen, we examine the evolution of ESSs using sensitivity analyses.

To carry out numerical experiments, the initial probability is set as $(0.5,0.2)$, and the initial parameter is set as $C_{d}=3, N E=12, C_{n}=24.6, R_{e}=2, R_{l}=4, S=2.5, A=1, B=5$ to meet the constraint conditions. We summarize the effect of the increase in each parameter under the three different emotion combinations on the probability of the government choosing the discharge policy $(p)$ and the probability of fishermen choosing to accept the discharge strategy $(q)$ in Table 6 and divide the parameters with similar changes to $p$ and $q$ into a group for discussion.

Table 6 Effect of the increase in each parameter on the probability of the government choosing the discharge policy $(p)$ and the probability of fishermen choosing to accept the discharge strategy $(q)$

\begin{tabular}{|c|c|c|c|c|c|c|}
\hline Parameters & \multicolumn{2}{|c|}{ Fishermen rational } & \multicolumn{2}{|c|}{ Fishermen pessimistic } & \multicolumn{2}{|c|}{ Fishermen optimistic } \\
\hline Probabilities & $p$ & $q$ & $p$ & $q$ & $p$ & $q$ \\
\hline $\begin{array}{r}C_{d}, R_{e}, N E \\
\text { (Dynamic) }\end{array}$ & $\begin{array}{l}\text { Slow } \\
\text { down }\end{array}$ & $\begin{array}{l}\text { Slow } \\
\text { down }\end{array}$ & Reduce & No effect & $\begin{array}{l}\text { Reduce and then } \\
\text { accelerate }\end{array}$ & Speed up \\
\hline$C_{n} \quad$ (Dynamic) & $\begin{array}{l}\text { Speed } \\
\text { up }\end{array}$ & $\begin{array}{l}\text { Speed } \\
\text { up }\end{array}$ & Increase & No effect & $\begin{array}{l}\text { Increase and then } \\
\text { slow down }\end{array}$ & Slow down \\
\hline$S$ (Dynamic) & $\begin{array}{l}\text { Slow } \\
\text { down }\end{array}$ & $\begin{array}{l}\text { Slow } \\
\text { down }\end{array}$ & Reduce & No effect & $\begin{array}{l}\text { Reduce and then } \\
\text { slow down }\end{array}$ & Slow down \\
\hline$B$ (Dynamic) & $\begin{array}{l}\text { No } \\
\text { effect }\end{array}$ & $\begin{array}{l}\text { No } \\
\text { effect }\end{array}$ & Reduce & No effect & $\begin{array}{l}\text { Unchanged and } \\
\text { then accelerate }\end{array}$ & Speed up \\
\hline$R_{l} \quad$ (Dynamic) & $\begin{array}{l}\text { Slow } \\
\text { down }\end{array}$ & $\begin{array}{l}\text { Speed } \\
\text { up }\end{array}$ & Increase & No effect & $\begin{array}{l}\text { Reduce and then } \\
\text { accelerate }\end{array}$ & Speed up \\
\hline$A$ (Dynamic) & $\begin{array}{l}\text { Speed } \\
\text { up }\end{array}$ & $\begin{array}{l}\text { Speed } \\
\text { up }\end{array}$ & Increase & No effect & $\begin{array}{l}\text { Unchanged and } \\
\text { then accelerate }\end{array}$ & Speed up \\
\hline $\begin{array}{cl}C_{d}, & R_{e}, N E, C_{n}, S, \\
B, & R_{l}, A \text { (Final result) }\end{array}$ & $\begin{array}{l}\text { Not } \\
\text { change }\end{array}$ & $\begin{array}{l}\text { Not } \\
\text { change }\end{array}$ & $\begin{array}{l}\text { Not } \\
\text { change }\end{array}$ & $\begin{array}{l}\text { Not } \\
\text { change }\end{array}$ & Not change & Not change \\
\hline
\end{tabular}

\subsubsection{Both sides of the game are rational}

When both sides of the game are rational, according to the effect of the increase in each parameter on the probability of the government choosing the discharge policy $(p)$ and the probability of fishermen choosing to accept the discharge strategy $(q)$, we can divide the parameters with similar changes into 4 groups. The effect of all parameter changes on $p$ 
and $q$ is summarized in Table 6 .

We carry out numerical simulations on the basis of controlling other variables unchanged and set $C_{d}=3,3.3,3.6, R_{e}=2,2.2,2.4, \quad N E=12,12.2,12.4, \quad S=2.5,2.7,2.9$. The specific evolution results are shown in Figs. $4(a)-4(h)$. It can be seen from the figures that the increase in these parameters will all slow the Japanese government's speed of promoting discharge policy and accelerate the evolution of Japanese fishermen's opposition strategy. For parameters $C_{d}$ and $S$, this may be because the rise in discharge costs and subsidies will increase its fiscal expenditure for the Japanese government, thus slowing down the evolution speed of its evolution to stabilize the 'Discharge' strategy. In addition, when the reputation gains that the government can make by choosing not to discharge become larger, this will certainly shake the government's determination to choose discharge, thus slowing down the rate at which the government chooses discharge policy; for fishermen, the government's willingness to discharge does not significantly decrease due to the increase of reputation, which makes them lose confidence of the government and speeds up their resistance. When the negative externalities of the marine environment faced by the Japanese government produced by discharge are larger, the government will certainly slow down the discharge for its own sake; however, the government's willingness to discharge remains high, and fishermen will speed up the resistance to protect their own interests according to the government's response. 


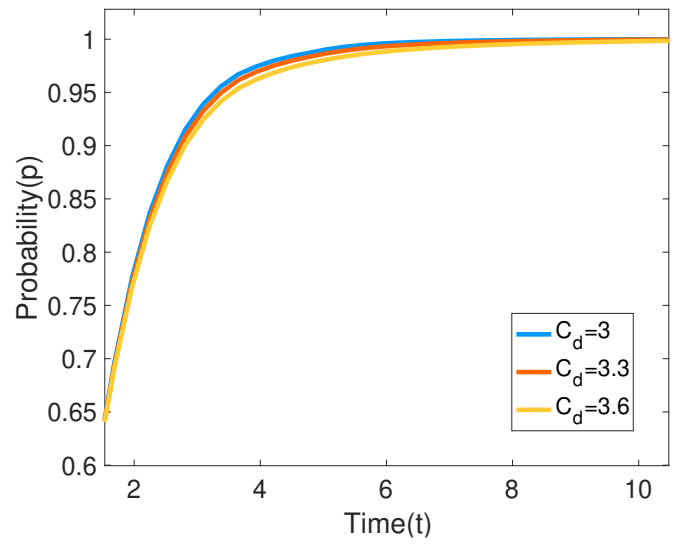

(a)

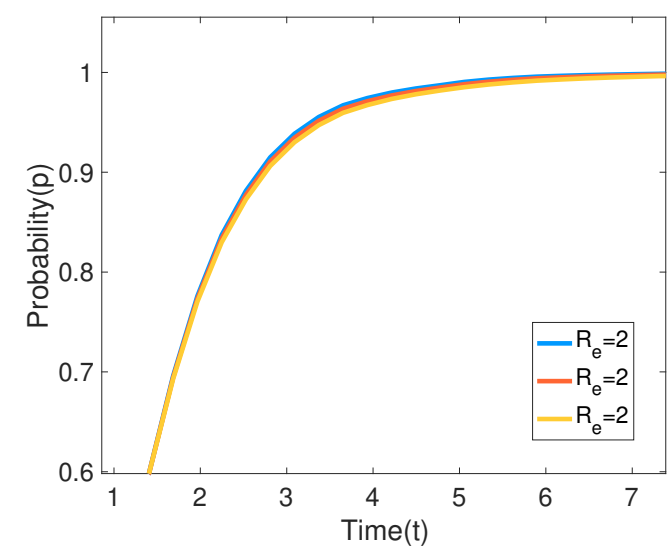

(c)

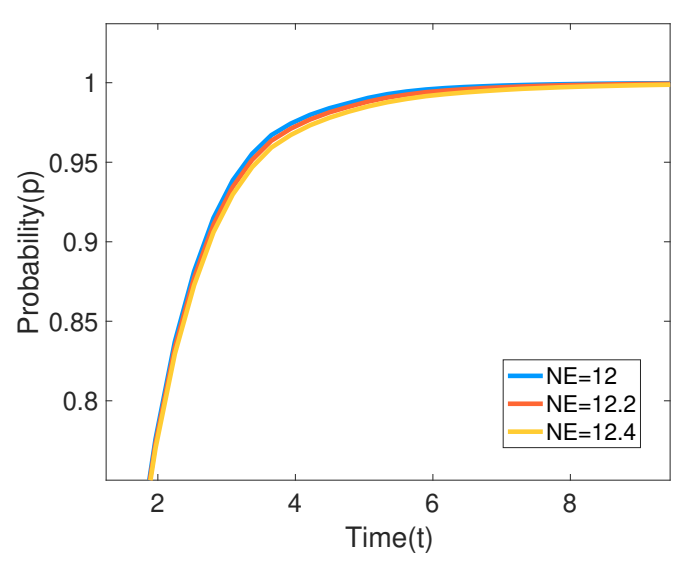

(e)

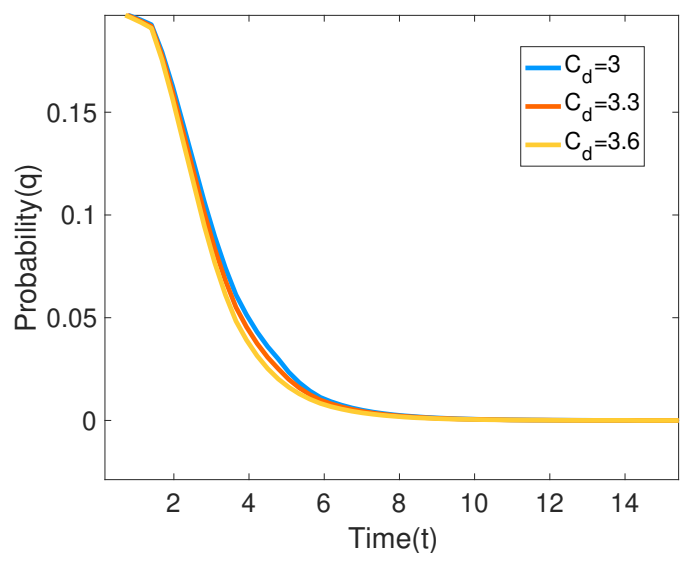

(b)

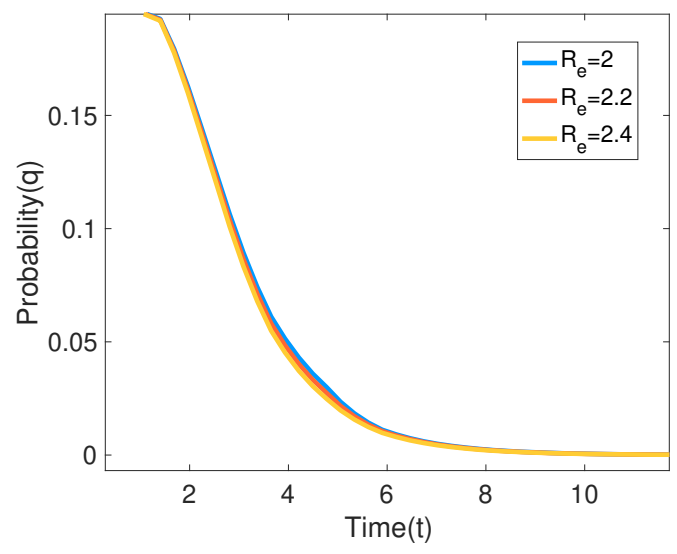

(d)

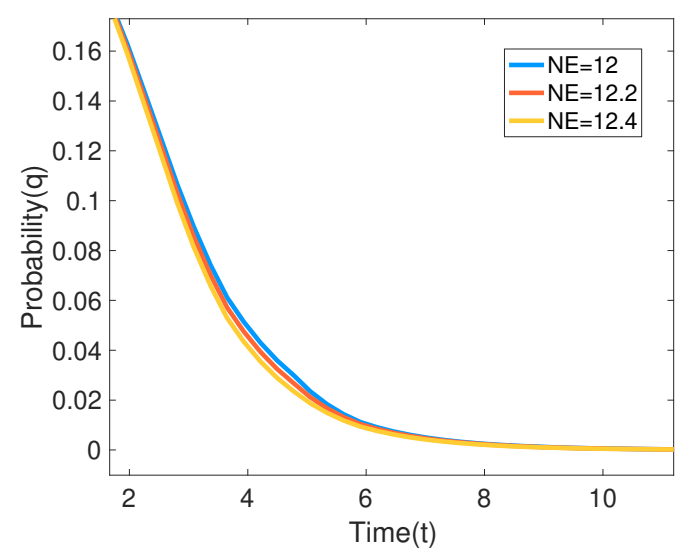

(f) 


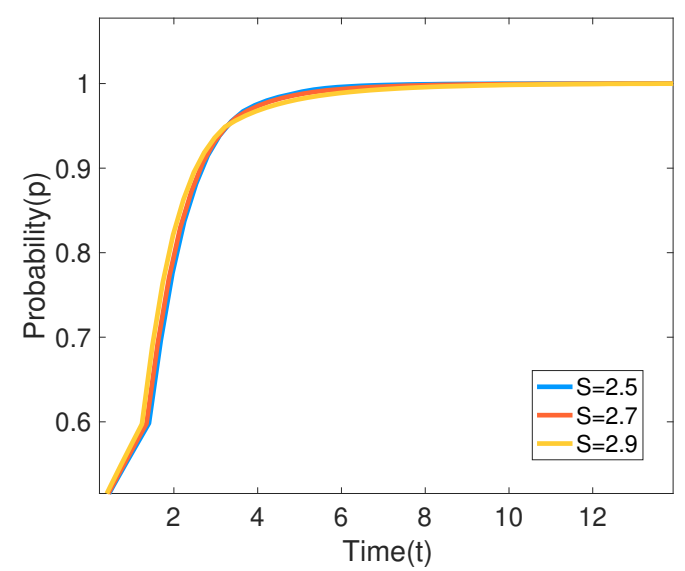

$(g)$

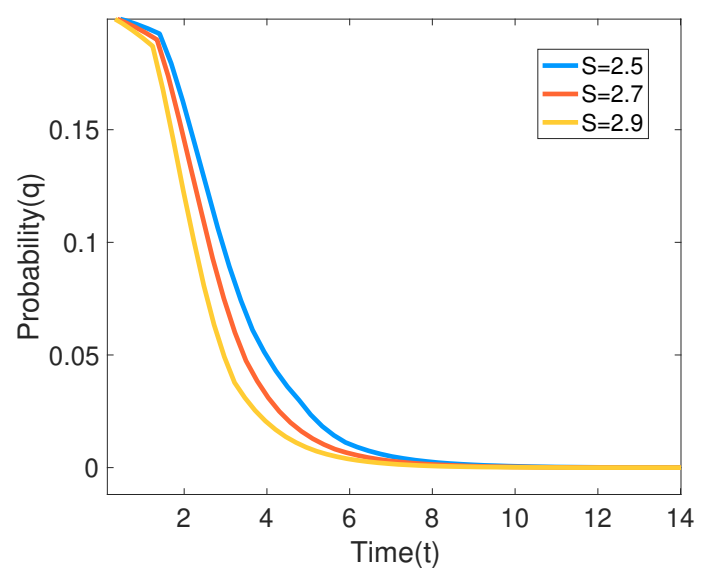

(h)

Fig. 4 Impact of parameters $C_{d}, R_{e}, N E$ and $S$ on evolutionary trajectories and results when fishermen are rational

Let $C_{n}=24.6,24.8,25$ and $A=0.96,0.98,1$, while keeping the other parameters unchanged. The evolution trajectory under different parameter values is shown in Figs. 5(a)5(d). The increase in $C_{n}$ and $A$ will accelerate the speed of the Japanese government's promotion of the wastewater discharge policy and slow down the evolution of Japanese fishermen's opposition strategy, which is the exact opposite of the changes in $p$ and $q$ brought by the above parameter changes such as $C_{d}$. For parameter $C_{n}$, this may be because the higher cost of nuclear wastewater treatment will definitely force the Japanese government back and accelerate the Japanese government's choice of nuclear wastewater discharge strategy. For parameter $A$, increasing protest costs reduces fishermen's willingness to protest, which accelerates the evolution of the government's discharge policy. 


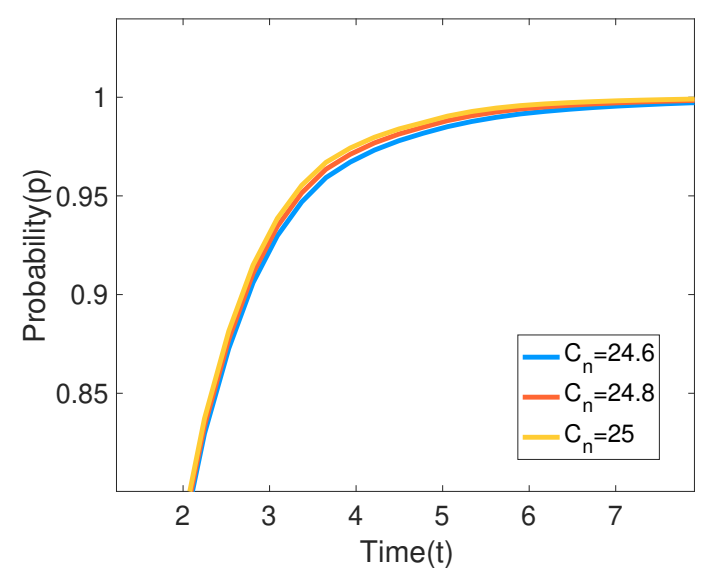

(a)

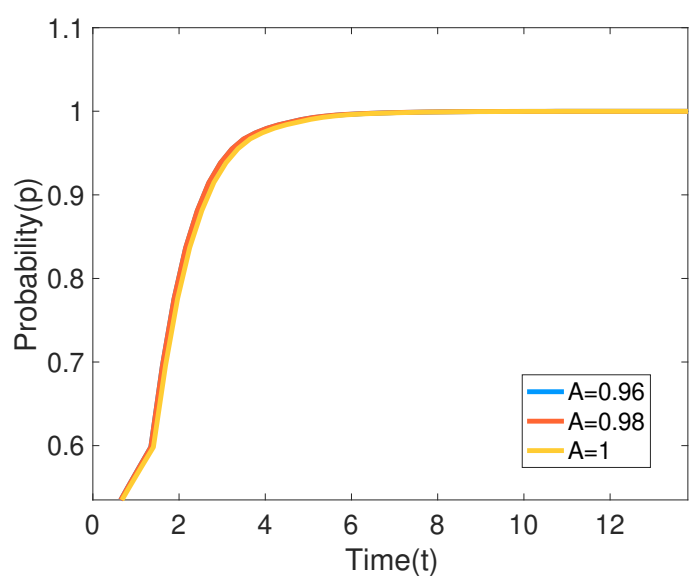

(c)

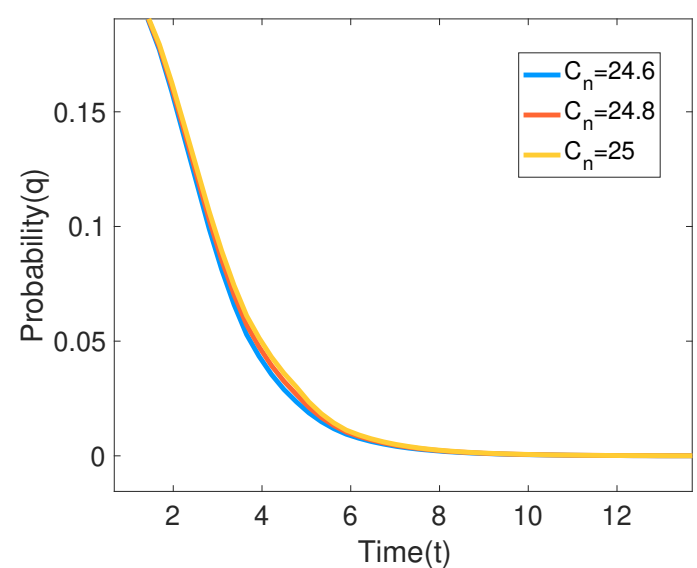

(b)

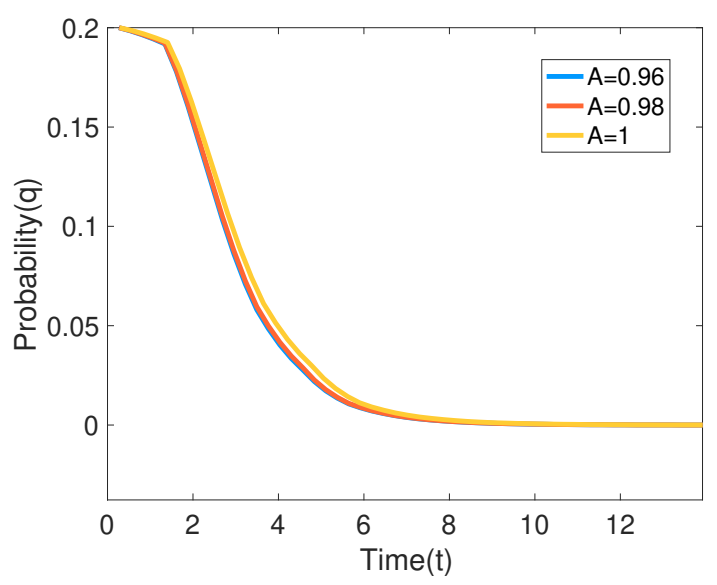

$(d)$

Fig. 5 Impact of parameters $C_{n}$ and $A$ on evolutionary trajectories and results when fishermen are rational

Let $B=5,5.2,5.4$, while keeping the other parameters unchanged. Figs. $6(a)-6(b)$ show the changes in evolutionary trajectories. However, we find that the changes in parameter $B$ will not have any influence on the evolution process of both sides. 


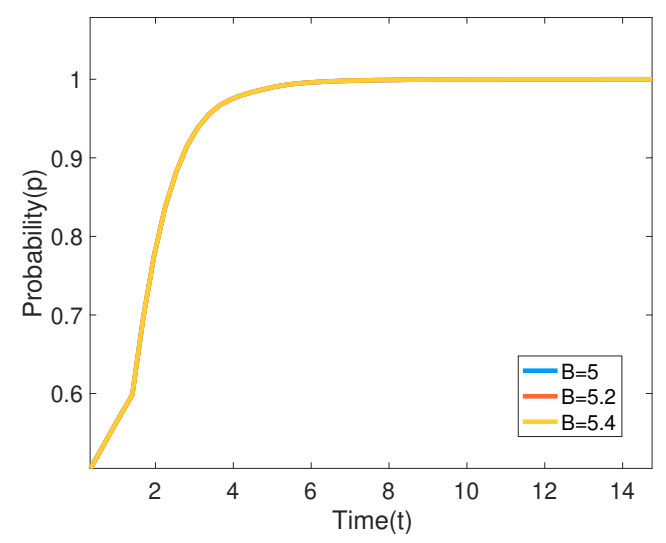

(a)

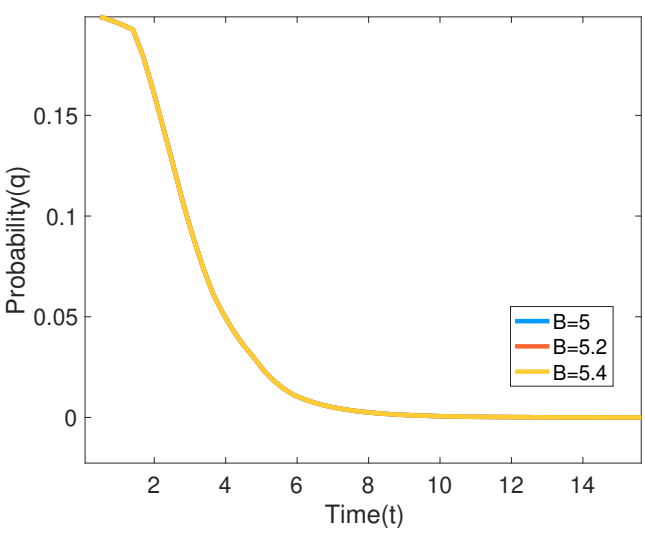

(b)

Fig. 6 Impact of parameter $B$ on evolutionary trajectories and results when fishermen are rational

For parameter $R_{l}$, we also control other variables unchanged, setting $R_{l}=3.6,3.8,4$, and we can obtain Figs. 7(a)-7(b). It can be seen that the increase in parameter $R_{l}$ will slow the speed at which the Japanese government promotes the discharge policy and the evolution of the opposition strategy of Japanese fishermen. This may be because the reputation loss caused by discharge is greater, and the government will certainly slow down the implementation of this policy for the sake of interest. However, the increase in reputation loss means that fishermen have stronger influence in the game, and under rational emotion, they will slow down resistance.

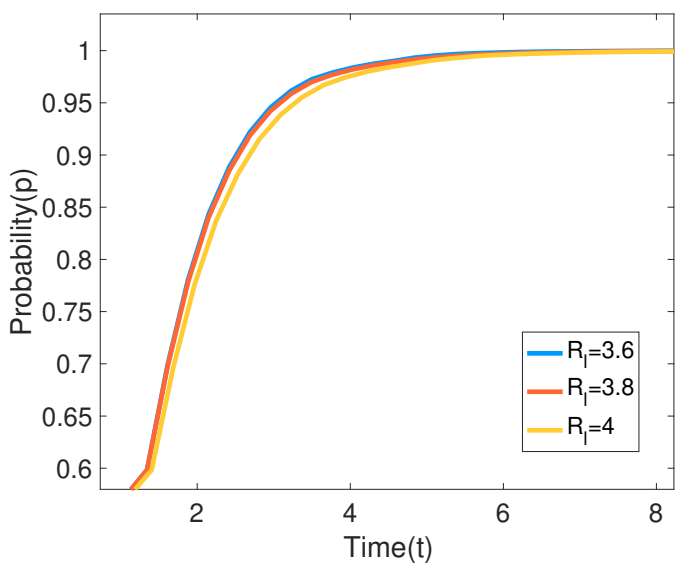

(a)

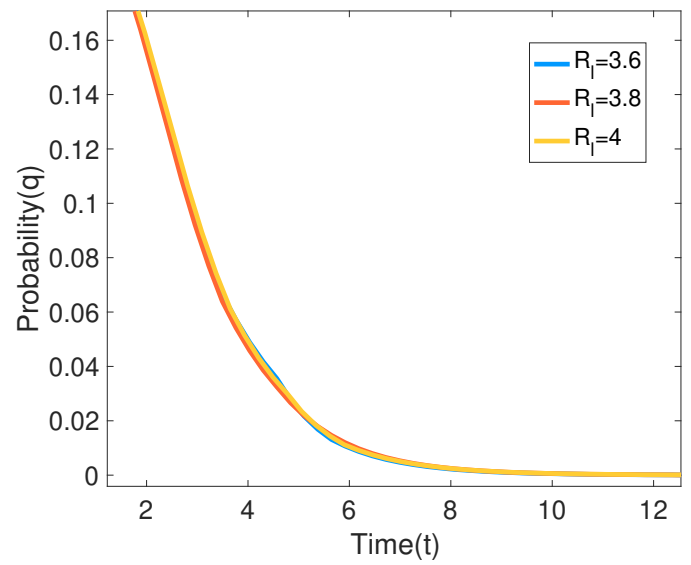

(b)

Fig. 7 Impact of parameter $R_{l}$ on evolutionary trajectories and results when fishermen are rational 


\subsubsection{The Japanese government is rational, Japanese fishermen are pessimistic}

Next, let us discuss the scenario in which the Japanese government is rational and Japanese fishermen are pessimistic. According to the parameter change impact on both sides of the game, the parameters with similar changes can be divided into 2 groups, and the effect of all parameter changes on $p$ and $q$ is summarized in Table 6.

Let $C_{d}=3,3.3,3.6, \quad R_{e}=2,2.2,2.4, \quad N E=12,12.2,12.4, \quad B=5,5.2,5.4, \quad S=2.5$, 2.7, 2.9, while keeping the other parameters unchanged. Figs. 8(a)-8(e) show that when Japanese fishermen are pessimistic, the increase in parameters $C_{d}, R_{e}, N E, B$ and $S$ reduces the probability that the Japanese government will push ahead with the nuclear wastewater discharge policy. We can find in the figures that the changes these parameters bring to the Japanese government's policy choices are similar to those when both parties are rational. Their increases have an inhibitory effect on the Japanese government's willingness to choose the discharge strategy. Moreover, when fishermen are pessimistic, the effect of the increase in these parameters on the probability of the government choosing the discharge strategy is more intuitive, which is reflected in the reduction in the value of $p$ at $\mathrm{t}=0$.

For parameter $B$, when both sides were rational, its increase will not have any influence on the evolution trajectory of both sides. In this situation, its increase reduces the government's willingness to promote the discharge policy. Perhaps the resolute resistance of fishermen in a pessimistic mood also makes the government realize that the discharge of nuclear wastewater is not good for the survival and life of the fishermen, and they will not make decisions based solely on their own interests. 
For fishermen, changes in the parameters will not change their willingness to choose the opposing strategy; no matter what the values of these parameters are, $q$ will decrease from 0.2 to 0 with the evolution process, as shown in Fig. 8(f).

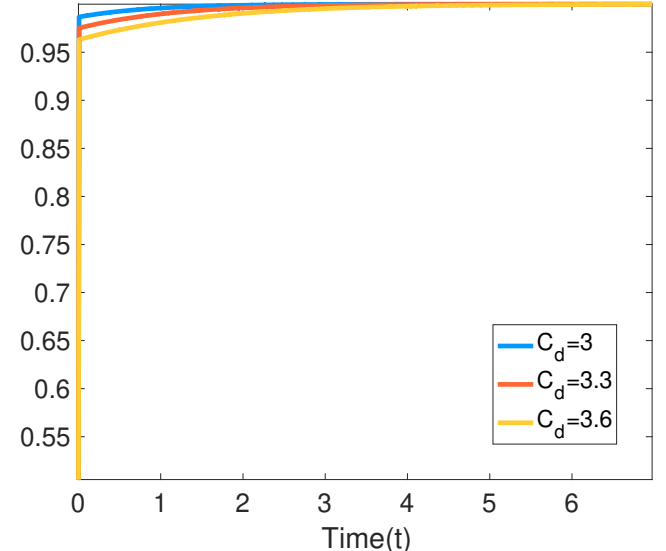

(a)

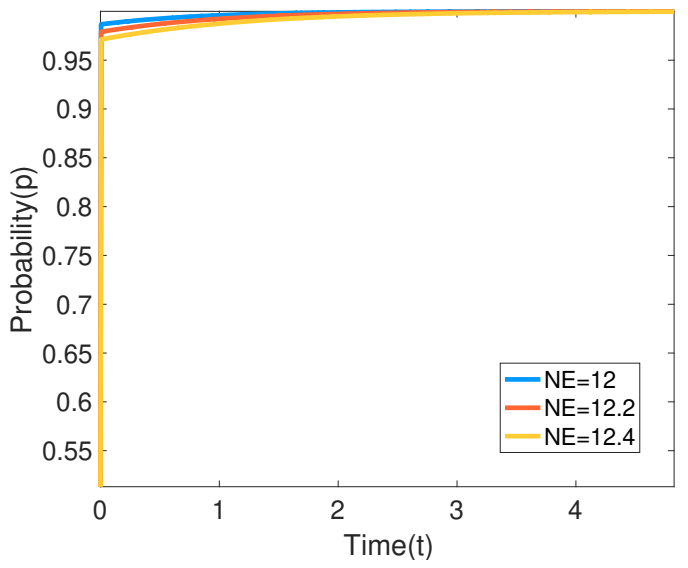

(c)

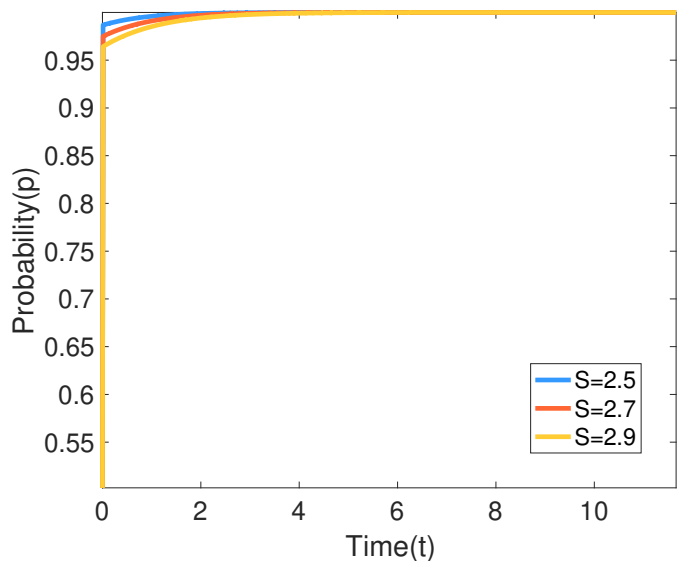

$(e)$

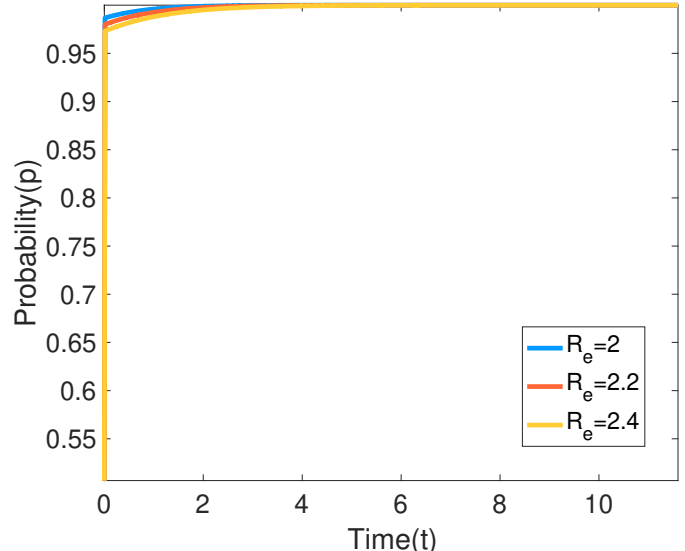

(b)

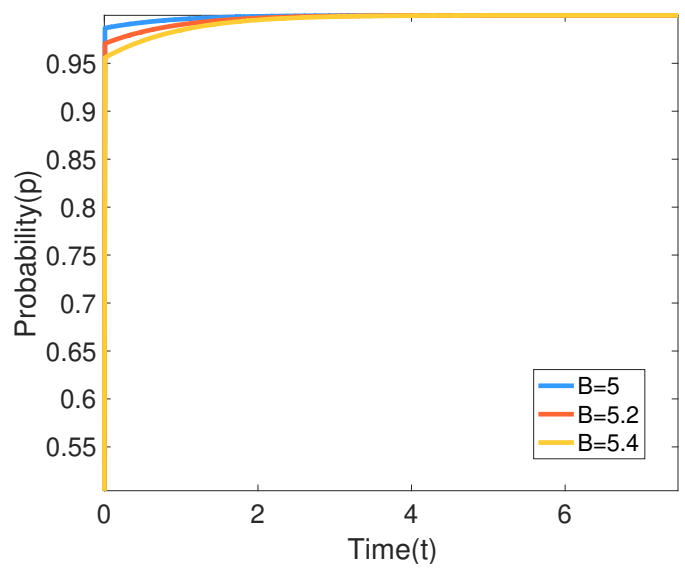

$(d)$

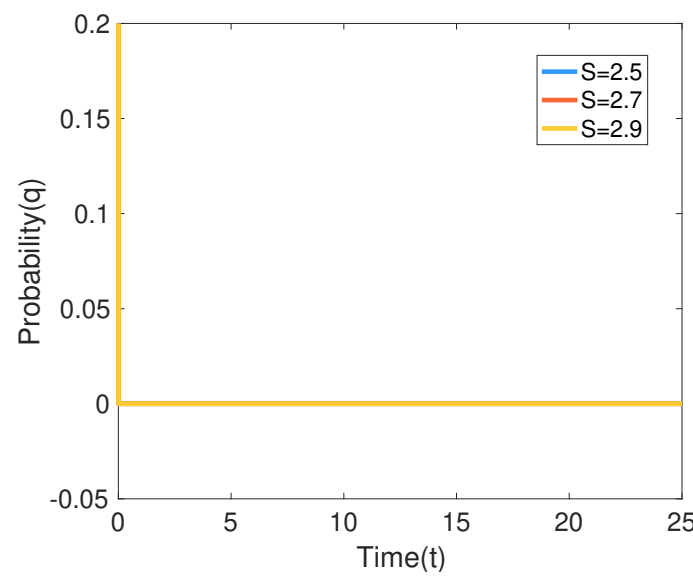

$(f)$

Fig. 8 Impact of parameters $C_{d}, R_{e}, N E, B$ and $S$ on evolutionary trajectories and results when fishermen are pessimistic 
In addition to the above parameters, we set $C_{n}=24.6,24.8,25, A=0.96,0.98,1$, $R_{l}=3.6,3.8,4$ to carry out the numerical simulation, and the specific results are shown in Figs. $9(a)-9(c)$. We find that the increases in parameters $C_{n}, A$ and $R_{l}$ all increase the probability that the Japanese government will push ahead with the policy of nuclear wastewater discharge. Regardless of how the parameters change, fishermen's determination to oppose the discharge of nuclear wastewater into the sea will not be shaken, and the evolutionary trajectory of the fishermen's choice of opposition strategy will not change, as shown in Fig. $9(d)$.

For parameter $R_{l}$, we note that, compared with the situation in which fishermen are rational, the change brought by reputation loss to the government's strategic choice changes from inhibiting the government to increasing the government's willingness to adopt the discharge strategy, which reflects that the emotional changes of fishermen will also affect the Japanese government's strategic choice intentions.

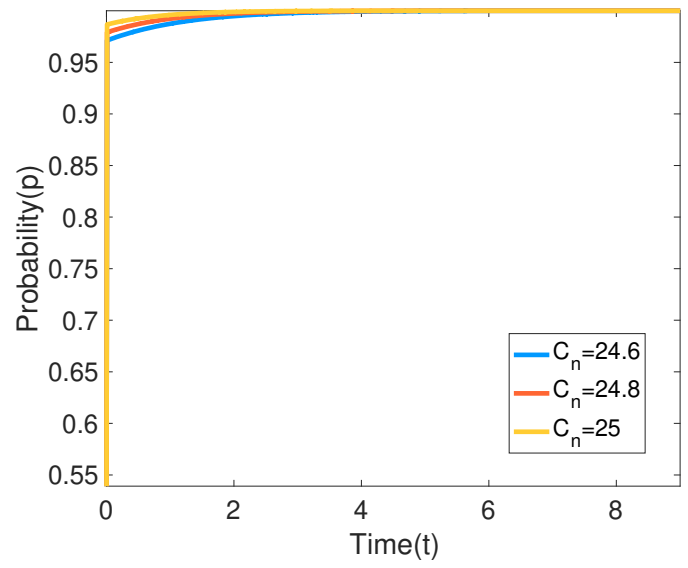

(a)

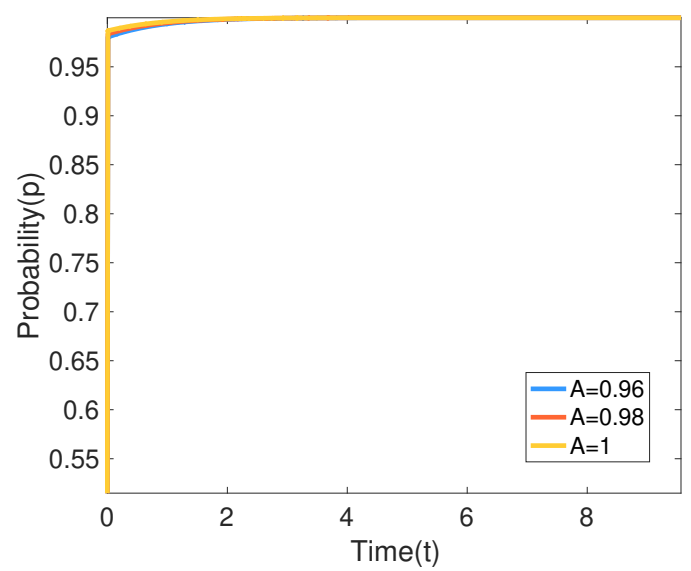

(b) 


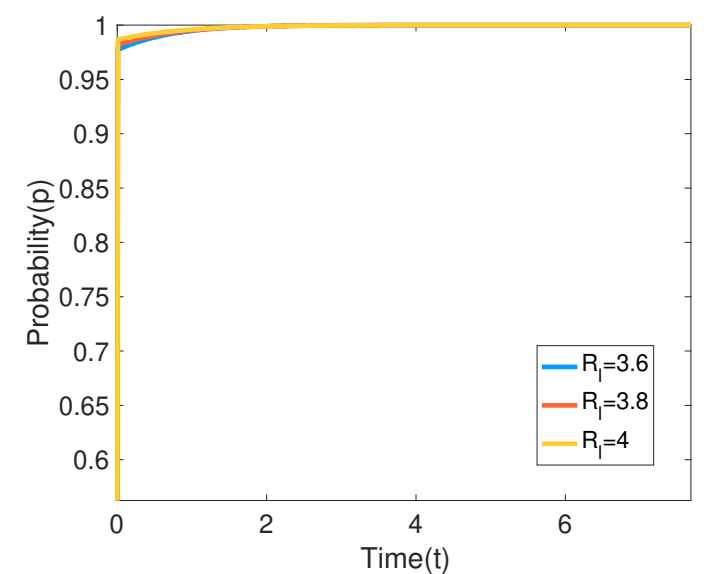

(c)

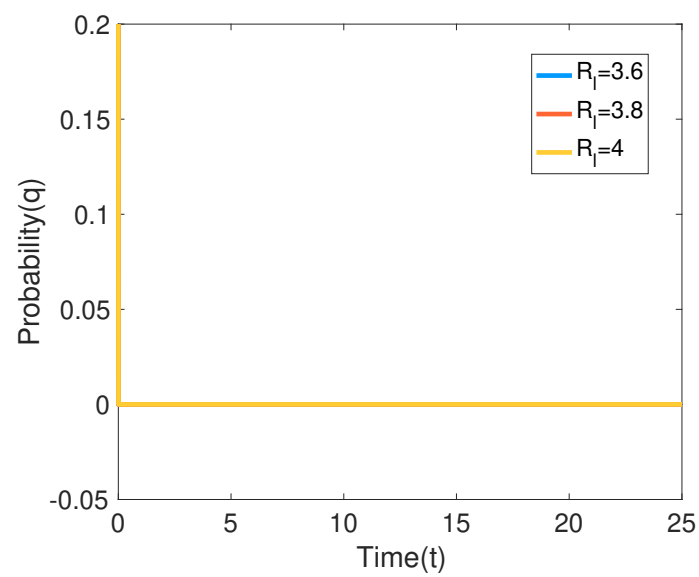

(d)

Fig. 9 Impact of parameters $C_{n}, A$ and $R_{l}$ on evolutionary trajectories and results when fishermen are pessimistic

\subsubsection{The Japanese government is rational, Japanese fishermen are optimistic}

Under the scenario in which the Japanese government is rational and Japanese fishermen are optimistic, the parameters with similar changes are divided into 4 groups, as shown in Figs. 10-13, and the effect of all parameter changes on $p$ and $q$ is summarized in Table 6 .

Similar to the above two scenarios, we set $C_{d}=3,3.3,3.6, R_{e}=2,2.2,2.4, \quad N E$ $=12,12.2,12.4, R_{l}=3.6,3.8,4$ while keeping the other parameters unchanged. As shown in Figs. 10(a)-10(h), when Japanese fishermen are optimistic, the increase in these parameters always reduces and then accelerates the probability of the Japanese government choosing the discharge policy and accelerates the speed at which Japanese fishermen choose to accept the discharge strategy, which is similar to the changes in the probability of the Japanese government choosing to discharge when both sides are rational, and they all inhibit the government's willingness to discharge.

For fishermen, the increase in discharge cost accelerates their choice of the 'Accept discharge' strategy, which may be because the blind trust of optimistic fishermen in the 
government makes them believe that when the discharge cost rises, the Japanese government will reduce the probability of their choice of discharge strategy. The increase in reputation gains will prompt Japanese fishermen to choose the strategy of accepting discharge more quickly because optimistic fishermen will have blind trust in the government. When the reputational benefits of the 'Nondischarge' increase, this kind of blind trust can lead them to believe that the government will consider them and change their strategic choices, so the increase in reputation gains will accelerate fishermen's choice to accept the discharge policy.

The change in strategy choice will be brought by the increase in reputation loss to both sides of the game, which may be because optimistic Japanese fishermen tend to trust the government. They will think that when the discharge strategy brings more reputation damage to the Japanese government, the government will definitely choose not to discharge nuclear wastewater into the sea. This overconfident speculation makes them choose the 'Accept discharge' strategy at an accelerated rate.

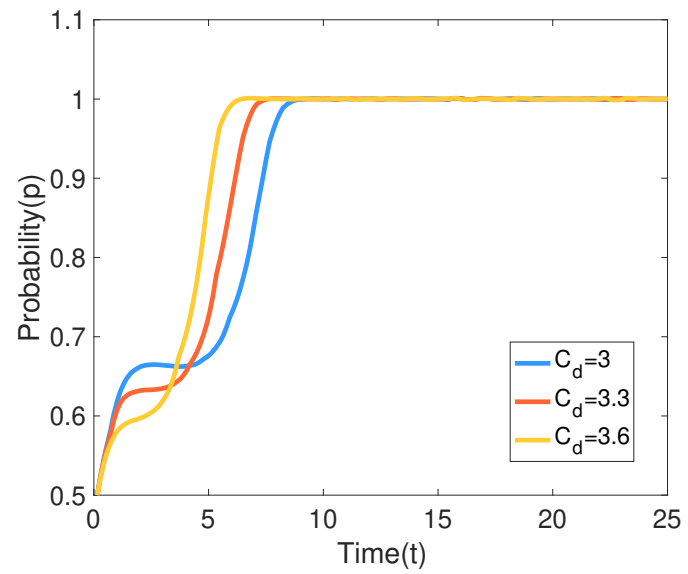

(a)

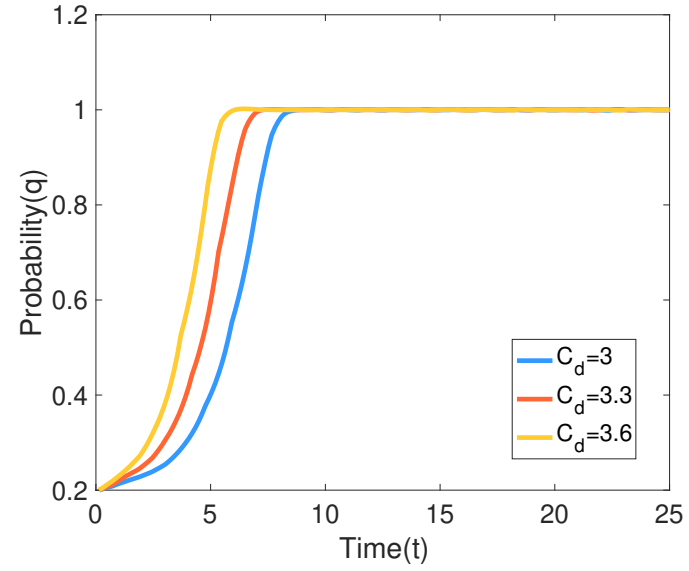

(b) 


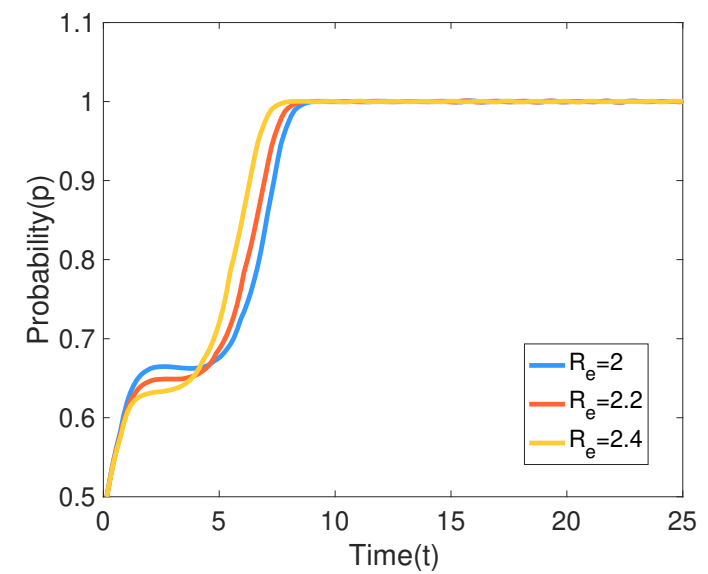

(c)

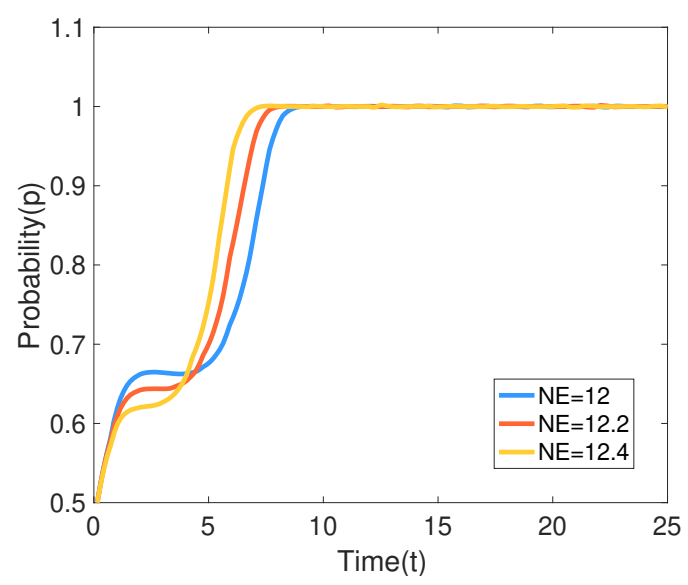

(e)

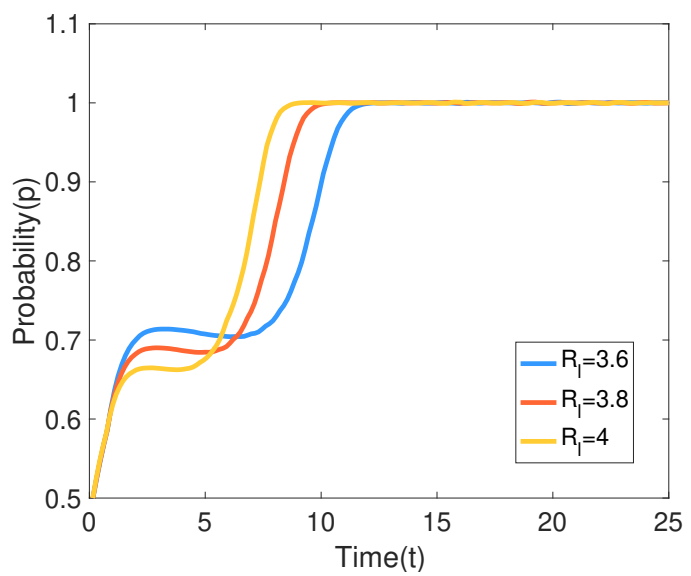

$(g)$

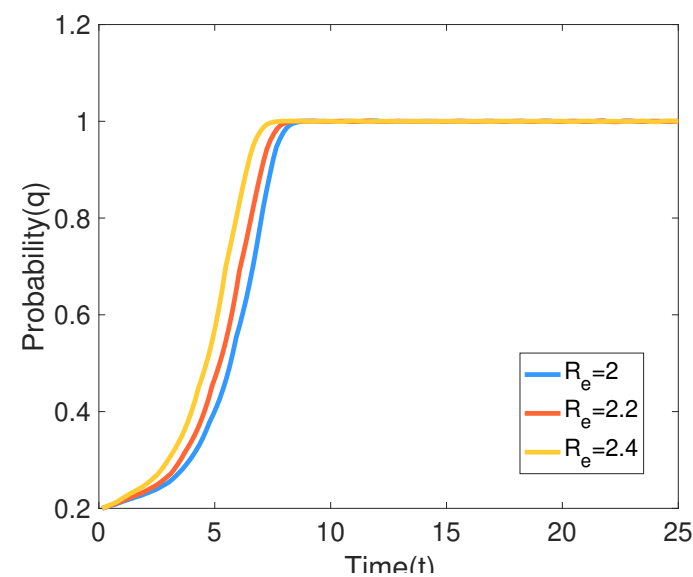

(d)

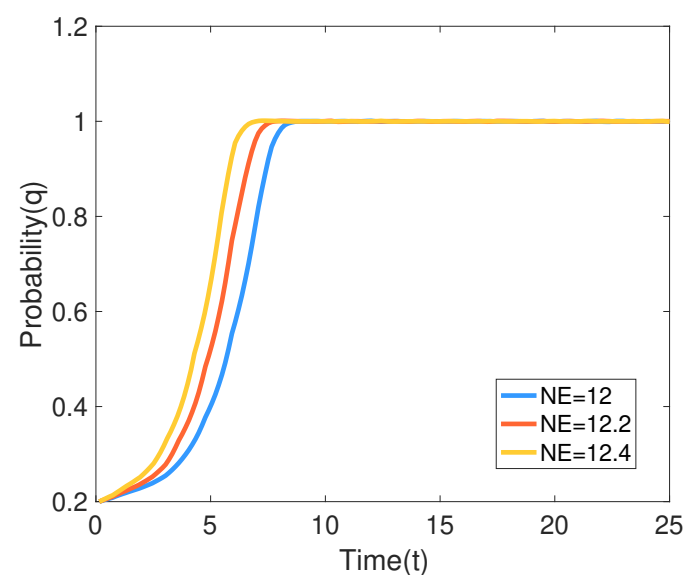

$(f)$

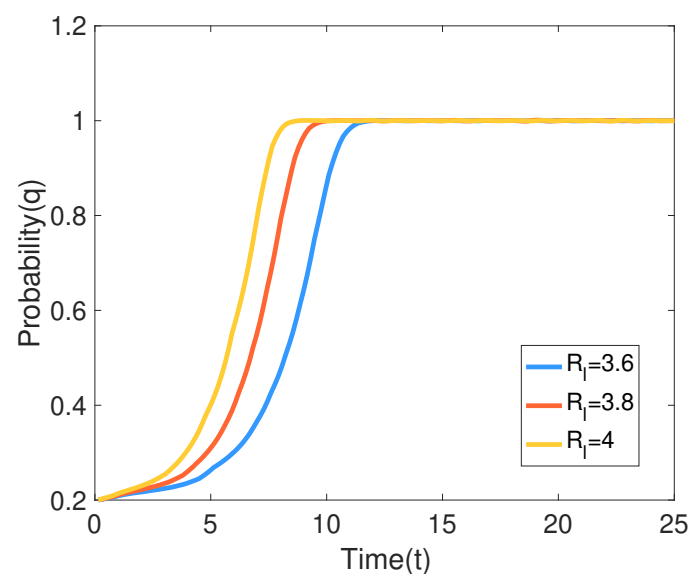

(h)

Fig. 10 Impact of parameters $C_{d}, R_{e}, N E$, and $R_{l}$ on evolutionary trajectories and results when fishermen are optimistic

In addition to the previous 4 parameters, the same as the above two scenarios, we require $S=2.5,2.7,2.9$ while keeping the other parameters unchanged, and the obtained results are shown in Figs. 11(a)-11(b). It can be seen from the figures that when Japanese 
fishermen are optimistic, the increase in parameter $S$ will reduce and slow the evolution of the Japanese government's choice of discharge strategies, and it will also slow down the rate at which Japanese fishermen choose the 'Accept discharge' strategy. This may be because although optimistic fishermen have great trust in the government, when they find that they can obtain more subsidies by choosing to oppose, the fishermen's determination will be shaken.

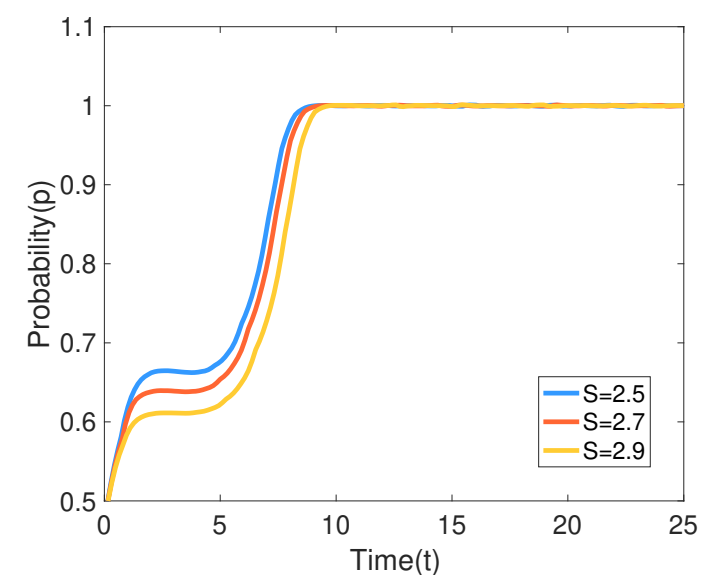

(a)

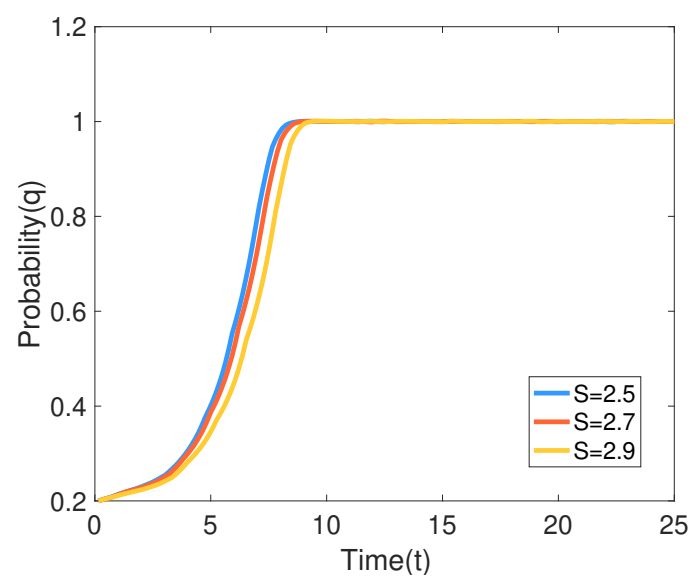

(b)

Fig. 11 Impact of parameter $S$ on evolutionary trajectories and results when fishermen are optimistic

Let $A=0.96,0.98,1$, while keeping the other parameters unchanged. As shown in Figs. 12(a)-12(b), the increase in fishermen's protest costs will further weaken their willingness to resist, which is reflected in the figures that the increase in $A$ accelerates the speed of the Japanese government's promotion of the wastewater discharge policy and the evolution of Japanese fishermen's acceptance strategy. For parameter $B$, we also set $B=5$, 5.2, 5.4 while keeping the other parameters unchanged; the results can be seen from Figs. $12(c)-12(d)$. With the growth of parameter $B$, the negative externalities of the marine environment will accelerate the evolution of fishermen's 'Accept discharge' strategy; that is, the higher the negative externality of the marine environment is, the faster the choice of the 
'Accept discharge' strategy. When the discharge of nuclear wastewater worsens their living environment, the evolution of fishermen's acceptance of discharge policies will be accelerated, indicating that optimism is not beneficial for them.

It is worth noting that the increase in parameter $B$ will have a reverse effect on the strategic choice of both parties under different emotion combinations. When both parties are rational, the increase in parameter $B$ has no effect on the evolutionary process of both parties; when fishermen are pessimistic, its increase reduces the government's willingness to discharge nuclear wastewater; and when fishermen are optimistic, the increase in parameter $B$ accelerates the government's choice of discharge. For fishermen themselves, the change in emotion will change their choice of equilibrium strategy. When they are rational and pessimistic, 'Oppose discharge' is their equilibrium strategy, while when they are optimistic, 'Accept discharge' is their equilibrium strategy. This once again reflects that the emotion changes of one party will affect the strategic choice of both sides in the game.

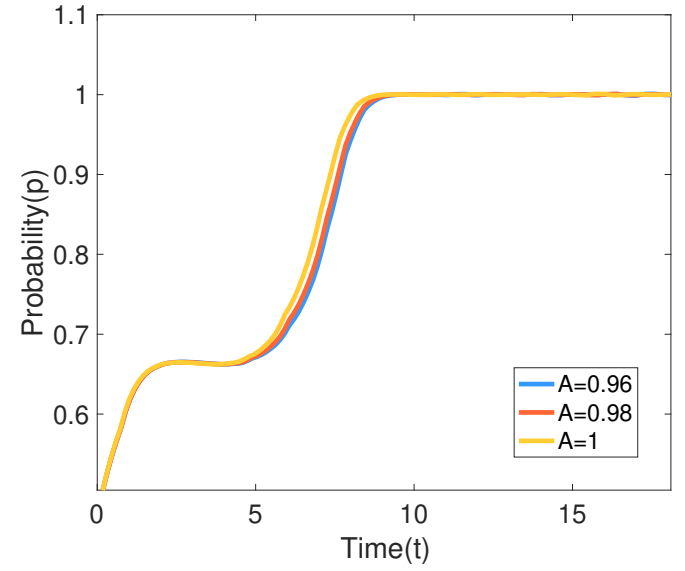

(a)

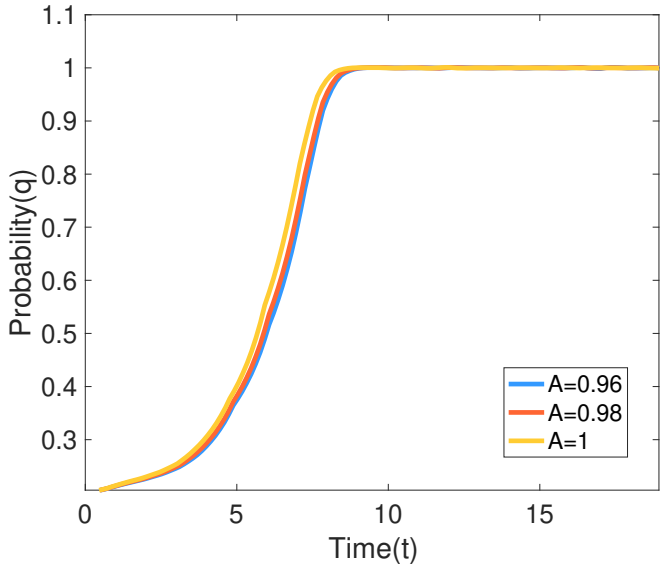

(b) 


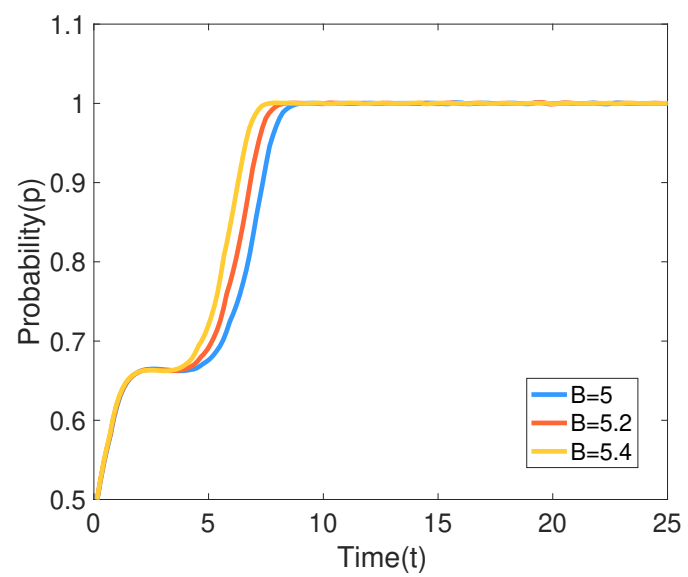

(c)

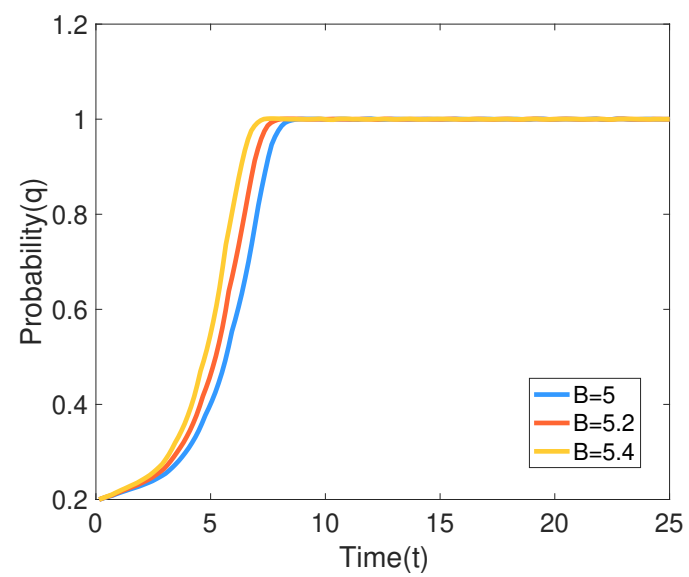

$(d)$

Fig. 12 Impact of parameters $A$ and $B$ on evolutionary trajectories and results when fishermen are optimistic

Then, let us discuss the impact of $C_{n}$ (the cost of nuclear wastewater treatment) on the game players. We require $C_{n}=24.6,24.8$, and 25 while keeping the other parameters unchanged, and then we can obtain the results shown in Figs. 13(a)-13(b). For the Japanese government, the increase in the cost of nuclear wastewater treatment will first increase the probability that the Japanese government will choose the discharge strategy and then will slow its evolution speed to the stable equilibrium point. Surprisingly, the increase in the cost of nuclear wastewater treatment will lead to a slowdown in the rate of fishermen at which they reach the stable equilibrium point $q=1$. This may be because, under the optimistic mood, although fishermen trust the Japanese government, they also understand that the high cost of nuclear wastewater treatment will force the Japanese government to retreat, thus slowing down the speed of its evolution to stabilize at the stable equilibrium point. 


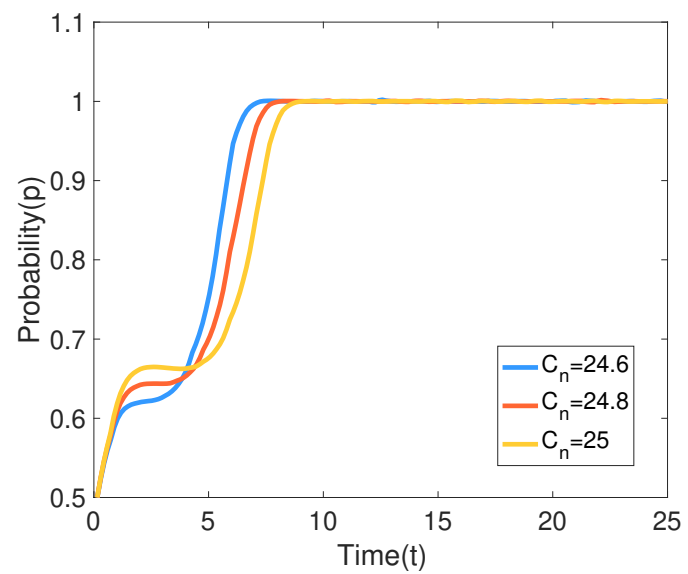

(a)

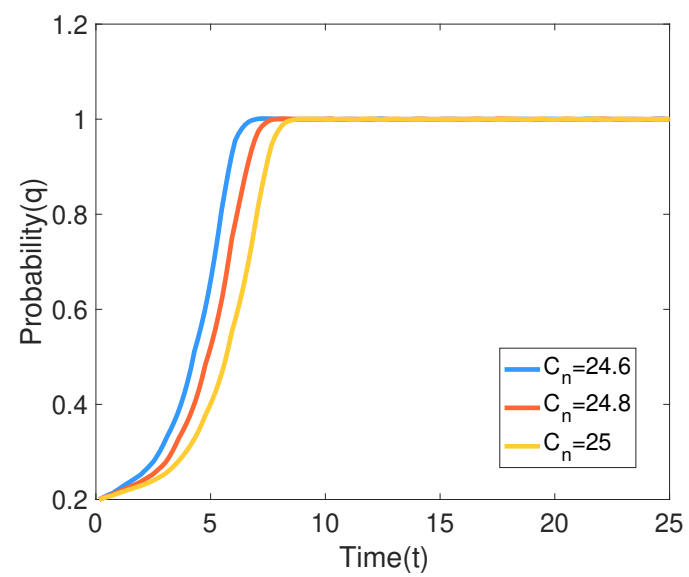

(b)

Fig. 13 Impact of parameter $C_{n}$ on evolutionary trajectories and results when fishermen are optimistic

In conclusion, fishermen under an optimistic mood will always accept the government's discharge policy, and blind trust under an optimistic mood always puts them in a disadvantageous situation.

Another point that needs to be explained is that although the change in parameters does not change the final evolutionary equilibrium strategy of the game between the two parties, the changes in these parameters have changed the trajectory of their evolution, indicating that the various factors represented by these parameters have an impact on the decision-making of both parties.

\subsection{Discussion}

This section uses numerical simulation to characterize the equilibrium decisions of the Japanese government and Japanese fishermen on nuclear wastewater discharge events. The different decisions of the two game subjects when the Japanese government is the rational player, while the Japanese fishermen are rational, pessimistic and optimistic, are compared. The effects of parameter changes on the evolution trajectories and results of both parties 
under different emotion combinations are discussed.

A summary and analysis of the results show that emotional changes will have an impact on the strategy choice of the players. When fishermen are rational and pessimistic, the equilibrium strategy of the evolutionary game is (Discharge, Oppose discharge), and when fishermen are optimistic, the equilibrium strategy of the evolutionary game is (Discharge, Accept discharge). However, under an optimistic mood, the equilibrium strategy of the game is unfavorable for fishermen, and we can find that when there is emotional influence, irrational selection behaviors will occur.

By grouping and comparing the numerical simulation results of parameters, we find that the increase in the cost of nuclear wastewater discharge, reputation gains, the negative externalities brought by the discharge of nuclear wastewater to the Japanese government's marine environment and government subsidies will reduce the probability of the Japanese government choosing the discharge strategy. The increase in the cost of nuclear wastewater treatment will always increase the probability that the Japanese government will choose the discharge strategy. The increase in subsidies will always increase the probability that fishermen will choose to oppose the discharge strategy. It shows that these parameters are the key external and internal interest factors that affect the game players' decision-making.

The emotional changes of Japanese fishermen not only affect the changes of their own strategies but also change the evolutionary trajectory of the Japanese government, although the strategy of the Japanese government has not undergone substantial changes. When the fishermen's emotions are different, the effects of parameters $R_{l}$ and $A$ on the government's discharge intention are different, indicating that the emotional changes of one 
party will also affect the strategic choice of the other party. However, there are still some limitations.

(1) The players in the RDEU evolutionary game need to be carefully screened. In this paper, the subjects of the RDEU evolutionary game of Japan's nuclear wastewater discharge event are the Japanese government and Japanese fishermen. However, in reality, the participants are not limited to them but may also involve many stakeholders, such as political parties of other countries, the United Nations and other international organizations. How to select participants and construct a more completed RDEU model is worth considering in the future.

(2) Emotional changes on both sides can be incorporated into the model framework at the same time. This paper constructs three situations in which the Japanese government is rational and Japanese fishermen are rational, pessimistic and optimistic. However, the decision of the Japanese government is likely to be emotional, and future research can consider the situation in which both sides of the game are emotional. It would be difficult to define the behavior of the Japanese government in times of optimism or pessimism.

(3) To facilitate the comparison of the parameter changes in the three scenarios, we narrowed the range of values. However, the values of the parameters are uncertain, and different values of the parameters in different scenarios can be considered in future research. 


\section{Conclusions and policy implications}

\subsection{Conclusions}

The Japanese government's intention to discharge Fukushima nuclear wastewater into the sea is a hot spot of concern of academia and politics. The latest research focuses on the game between Japan and relevant external interest groups, such as Liu, Lyu, et al. (2021) and Liu, Wang, et al. (2021). Unlike the abovementioned literature, the research object of this paper is the Japanese government and fishermen. Meanwhile, we also consider the evolution of players' decisions from a dynamic perspective. Overall, this paper develops an RDEU evolutionary game model considering the impact of participants' emotions. Through numerical simulation, the ESSs under three emotion combinations and the effect of parameters on the evolutionary trajectory and results of both parties are described. Based on the experimental results, the following conclusions are obtained.

First, when there is emotional influence, the evolutionary stability strategy of the game party will change, and when the fishermen are optimistic, irrational choice behavior will occur. Second, emotions are contagious to a certain extent, and the strategic changes caused by one party's emotional changes will also indirectly affect the other party's strategic choice intentions. Third, by comparison, reducing the cost of nuclear waste disposal is currently the most feasible way to reduce the probability of the Japanese government's discharge policy. Under the premise that the government chooses the discharge strategy, no matter what the fishermen's emotions are, it is the fishermen's dominant strategy to strive for more subsidies for their own interests. 


\subsection{Policy implications}

Based on the abovementioned conclusions, the following policy implications are proposed from the perspectives of the Japanese government and Japanese fishermen to strengthen the Japanese government's strategic shift from discharge to nondischarge policy and to minimize the losses of Japanese fishermen under the insistence of the Japanese government.

The first is to establish an emotional dredging mechanism to control public sentiment. The results of the evolutionary game show that when fishermen are pessimistic, their resistance is extremely strong, and changes in the external environmental factors represented by the parameters will hardly change their determination to choose resolute resistance. At this time, emotional counseling is particularly important. To resolve the pessimism of fishermen, special emotional evacuation systems and special emotional evacuation agencies can be established. The government can also dispatch professional handlers and relevant public officials to answer questions from the fishermen, making the entire incident handling process transparent, to ease the fishermen's protesting emotions and then effectively control public sentiment to avoid disturbing the national order.

Second, appropriate subsidy strategies should be formulated for fishermen according to their emotions. The results of numerical simulation show that regardless of the emotion combination of the two parties, an increase in subsidies can always increase the willingness of fishermen to resist. However, under different emotions, they made different decisionmaking choices, both accepting and opposing. Under rational and pessimistic emotions, fishermen have a strong sense of resistance, and we can understand this resistance as 'selfdefense'. While under optimism, it is fishermen's self-interest performance. Therefore, when 
the government formulates a subsidy strategy, it should extensively listen to public opinion, understand and grasp the emotions of the fishermen, and then carefully study and determine the fishermen's subsidy strategy. When the fishermen are rational, the government can comfort their resistance through moderate subsidies; when the fishermen are pessimistic, the government can increase subsidies to slow down the fishermen's fighting spirit, regain the public's trust, and then let them return to rational negotiations; when the fishermen are optimistic, subsidies can be appropriately reduced. However, no matter how the subsidies are, the government should actively seek better methods of nuclear wastewater treatment. After all, the environmental pollution caused by the discharge of nuclear wastewater is irreversible. The increase in subsidies can only temporarily alleviate the game relationship of this incentive and cannot fundamentally solve a series of problems caused by discharge.

The third is to focus on reducing the cost of nuclear wastewater treatment and establish a mechanism for expressing interest demands to increase the public's confidence in negotiations and games. The government should understand that under pessimism, the fishermen's resistance logic of 'resolute resistance' is because they do not have enough sense of security. Numerical simulation results show that changes in the cost of nuclear wastewater treatment will have a significant impact on the game behavior of both parties. The Japanese government should try to find other and better ways to deal with nuclear wastewater so that fishermen feel that their demands are taken seriously to enhance public trust. At the same time, it is also necessary to establish a mechanism for the expression of fishermen's interests and demands to reduce the degree of information asymmetry and promote the establishment of an equal dialog mechanism between the two sides to ensure a smooth and effective 
communication mechanism and ultimately improve the public's confidence in negotiations and games. It can also mobilize the forces within the government to participate in the interaction with the fishermen and truly consider the interests of the masses.

\section{Acknowledgments}

The authors would like to express their gratitude for the support provided by the National Natural Science Foundation of China [grant numbers 72071025, 72072097, 72001120 and 72101129], the Social Science Planning Foundation of Liaoning [grant number L19BGL005], the Natural Science Foundation of Liaoning Province [grant number 2020-HYLH-39], the Special Foundation for Basic Scientific Research of the Central Colleges of China [grant number 3132021254] and the School-level Scientific Research Project of Beijing Wuzi University [grant number 2021XJKY10].

\section{Declaration of interest statement}

The authors declare that they have no known competing financial interests or personal relationships that could have appeared to influence the work reported in this paper.

\section{References}

Amano, Y. (2015). The Fukushima Daiichi accident. Le Nucléaire Un An Après Fukushima. Buesseler, K. O. (2014). Fukushima and ocean radioactivity. Oceanography, 27(1), 92-105. Butler, C., Parkhill, K. A., \& Pidgeon, N. F. (2011). Nuclear power after Japan: The social dimensions. Environment: Science and Policy for Sustainable Development, 53(6), 314.

Chen, W., \& Hu, Z.-H. (2018). Using evolutionary game theory to study governments and manufacturers' behavioral strategies under various carbon taxes and subsidies. Journal of Cleaner Production, 201, 123-141.

Cléro, E., Ostroumova, E., Demoury, C., Grosche, B., Kesminiene, A., Liutsko, L., Motreff, Y., Oughton, D., Pirard, P., \& Rogel, A. (2021). Lessons learned from Chernobyl and Fukushima on thyroid cancer screening and recommendations in case of a future nuclear accident. Environment International, 146, 106230. 
Clifford, D., \& Zhang, Z. (1994). Modifying ion exchange for combined removal of uranium and radium. Journal-American Water Works Association, 86(4), 214-227.

Coninx, K., Deconinck, G., \& Holvoet, T. (2018). Who gets my flex? An evolutionary game theory analysis of flexibility market dynamics. Applied energy, 218, 104-113.

Cullen-Knox, C., Haward, M., Jabour, J., Ogier, E., \& Tracey, S. R. (2017). The social licence to operate and its role in marine governance: insights from Australia. Marine Policy, 79, 70-77.

de With, G., Bezhenar, R., Maderich, V., Yevdin, Y., Iosjpe, M., Jung, K., Qiao, F., \& Perianez, R. (2021). Development of a dynamic food chain model for assessment of the radiological impact from radioactive releases to the aquatic environment. Journal of environmental radioactivity, 233, 106615.

Dufresne, C., Duffa, C., Rey, V., \& Verney, R. (2018). Hydro-sedimentary model as a postaccidental management tool: application to radionuclide marine dispersion in the Bay of Toulon (France). Ocean \& Coastal Management, 153, 176-192.

Estalaki, S. M., Abed-Elmdoust, A., \& Kerachian, R. (2015). Developing environmental penalty functions for river water quality management: application of evolutionary game theory. Environmental Earth Sciences, 73(8), 4201-4213.

Ethel, I., Muktar, K., Saiyadi, S., \& Oruru, J. (2011). Nuclear Accident in Japan March 2011. Fernandez, L., Kaiser, B., Moore, S., \& Vestergaard, N. (2016). Introduction to special issue: Arctic marine resource governance. Marine Policy, 72, 237-239.

Friedman, D. (1991). Evolutionary games in economics. Econometrica: Journal of the Econometric Society, 59(3), 637-666.

Friedman, D. (1998). On economic applications of evolutionary game theory. Journal of evolutionary economics, 8(1), 15-43.

Gallardo, A. H., \& Marui, A. (2016). The aftermath of the Fukushima nuclear accident: Measures to contain groundwater contamination. Science of the total environment, $547,261-268$.

Hanley, N., \& Folmer, H. (1998). Game theory and the environment. Edward Elgar. 
Hao, X., Yan, Z., \& De Qing, T. (2019). Evolutionary equilibrium analysis of the influence of participants' emotions on environmental NIMBY conflict. Soft Science, 33(3), 121126.

Hong, K., Zou, Y., Zhang, Y., \& Duan, K. (2020). The weapon of the weak: An analysis of RDEU game in the conflict of farmland expropriation under the influence of emotion. Sustainability, 12(8), 3367.

Hujainah, F., Bakar, R. B. A., Al-Haimi, B., \& Abdulgabber, M. A. (2018). Stakeholder quantification and prioritisation research: A systematic literature review. Information and Software Technology, 102, 85-99.

Iwasa, M., Nakaya, F., Kabeya, H., Sato, K., Ishikawa, S.-i., \& Takahashi, T. (2020). Radiocesium concentrations in invertebrates and their environmental media at two distances from the Fukushima Dai-ichi Nuclear Power Plant during 3-6 years after the 2011 accident. Environmental Pollution, 267, 115657.

Khajeh, M., Sarafraz-Yazdi, A., \& Moghadam, A. F. (2017). Modeling of solid-phase tea waste extraction for the removal of manganese and cobalt from water samples by using PSO-artificial neural network and response surface methodology. Arabian Journal of Chemistry, 10, S1663-S1673.

Khani, M., Pahlavanzadeh, H., \& Alizadeh, K. (2012). Biosorption of strontium from aqueous solution by fungus Aspergillus terreus. Environmental Science and Pollution Research, 19(6), 2408-2418.

Kuroda, Y., Goto, A., Terauchi, H., \& Suzuki, S. (2021). Change in sense of food safety associated with social connectedness and information sources-A 10-year longitudinal survey before and after the Fukushima nuclear power plant accident. Public Health, 194, 156-162.

Liu, J., Lyu, Y., Zhao, H., \& Chen, J. (2021). Game analysis of nuclear wastewater discharge under different attitudes: Seeking a potential equilibrium solution. Science of the total environment, 801, 149762.

Liu, J., Wang, X., Tan, Z., \& Chen, J. (2021). A tripartite evolutionary game analysis of Japan's nuclear wastewater discharge. Ocean \& Coastal Management, 214, 105896. 
Lv, J., Lin, M., \& Zhou, W. (2021). Fluctuation in construction costs and its effect on contract renegotiation behavior in PPP wastewater treatment projects: An evolutionary game analysis. Journal of Cleaner Production, 128025.

Moriyama, N., Nakayama, C., Orui, M., Kuroda, Y., Iwasa, H., Horiuchi, T., Nakayama, T., Sugita, M., \& Yasumura, S. (2020). Associated factors related to participation in general health checkup and survey of the effect of low-dose radiation exposure on health of residents of Fukushima Prefecture after the Fukushima Daiichi nuclear power plant accident. Preventive Medicine Reports, 20, 101214.

Normile, D. (2021). Japan plans to release Fukushima's wastewater into the ocean. Science, April, 13, 2021.

Okamura, H., Ikeda, S., Morita, T., \& Eguchi, S. (2016). Risk assessment of radioisotope contamination for aquatic living resources in and around Japan. Proceedings of the National Academy of Sciences, 113(14), 3838-3843.

Penz, E., \& Polsa, P. (2018). How do companies reduce their carbon footprint and how do they communicate these measures to stakeholders? Journal of Cleaner Production, $195,1125-1138$.

Quiggin, J. (1982). A theory of anticipated utility. Journal of Economic Behavior \& Organization, 3(4), 323-343.

Quiggin, J. . (1991). Comparative statics for rank-dependent expected utility theory. Journal of Risk and Uncertainty, 4, 339-350.

Shozugawa, K., Hori, M., Johnson, T. E., Takahata, N., Sano, Y., Kavasi, N., Sahoo, S. K., \& Matsuo, M. (2020). Landside tritium leakage over through years from Fukushima Dai-ichi nuclear plant and relationship between countermeasures and contaminated water. Scientific Reports, 10(1), 1-9.

Smith, G. (2018). Good governance and the role of the public in Scotland's marine spatial planning system. Marine Policy, 94, 1-9.

Smythe, T. C., \& McCann, J. (2018). Lessons learned in marine governance: Case studies of marine spatial planning practice in the US. Marine Policy, 94, 227-237. 
Starmer, C. (2000). Developments in non-expected utility theory: The hunt for a descriptive theory of choice under risk. Journal of economic literature, 38(2), 332-382.

Steinhauser, G., Brandl, A., \& Johnson, T. E. (2014). Comparison of the Chernobyl and Fukushima nuclear accidents: a review of the environmental impacts. Science of the total environment, 470, 800-817.

Su, Y. (2020). Multi-agent evolutionary game in the recycling utilization of construction waste. Science of the total environment, 738, 139826.

Sun, H., Wan, Y., Zhang, L., \& Zhou, Z. (2019). Evolutionary game of the green investment in a two-echelon supply chain under a government subsidy mechanism. Journal of Cleaner Production, 235, 1315-1326.

Tanaka, S., Hatakeyama, K., Takahashi, S., \& Adati, T. (2016). Radioactive contamination of arthropods from different trophic levels in hilly and mountainous areas after the Fukushima Daiichi nuclear power plant accident. Journal of environmental radioactivity, 164, 104-112.

Tims, S., Froehlich, M., Fifield, L., Wallner, A., \& De Cesare, M. (2016). 236U and 239,240 $\mathrm{Pu}$ ratios from soils around an Australian nuclear weapons test site. Journal of environmental radioactivity, 151, 563-567.

Tsabaris, C., Tsiaras, K., Eleftheriou, G., \& Triantafyllou, G. (2021). 137Cs ocean distribution and fate at East Mediterranean Sea in case of a nuclear accident in Akkuyu Nuclear Power Plant. Progress in Nuclear Energy, 139, 103879.

Von Neumann, J., \& Morgenstern, O. (2007). Theory of games and economic behavior. Princeton university press.

Wang, G., Chao, Y., Jiang, T., \& Chen, Z. (2021). Facilitating developments of solar thermal power and nuclear power generations for carbon neutral: A study based on evolutionary game theoretic method. Science of the total environment, 814, 151927.

Weibull, J. W. (1997). Evolutionary game theory. MIT press.

Xiong, G., \& Hou, Y. (2012). The game model with emotional factors of public and media in public emergencies management engineering. Systems Engineering Procedia, 5, 228233. 
Xu, L., Di, Z., \& Chen, J. (2021). Evolutionary game of inland shipping pollution control under government co-supervision. Marine Pollution Bulletin, 171, 112730.

Yaari, M. E. (1987). The dual theory of choice under risk. Econometrica: Journal of the Econometric Society, 55(1), 95-115.

Yang, B., Yin, K., Li, X., \& Liu, Z. (2022). Graph model under grey and unknown preferences for resolving conflicts on discharging Fukushima nuclear wastewater into the ocean. Journal of Cleaner Production, 332, 130019.

Yankovich, T., Kim, S., Baumgärtner, F., Galeriu, D., Melintescu, A., Miyamoto, K., Saito, M., Siclet, F., \& Davis, P. (2011). Measured and modelled tritium concentrations in freshwater Barnes mussels (Elliptio complanata) exposed to an abrupt increase in ambient tritium levels. Journal of environmental radioactivity, 102(1), 26-34.

Zhang, X., Qu, T., \& Wang, Y. (2022). Optimal strategies for stakeholders of Fukushima nuclear waste water discharge in Japan. Marine Policy, 135, 104881.

Zhao, C., Wang, G., Zhang, M., Wang, G., de With, G., Bezhenar, R., Maderich, V., Xia, C., Zhao, B., \& Jung, K. T. (2021). Transport and dispersion of tritium from the radioactive water of the Fukushima Daiichi nuclear plant. Marine Pollution Bulletin, $169,112515$. 